\title{
Explaining the Boom-Bust Cycle in the U.S. Housing Market: A Reverse-Engineering Approach
}

\author{
Paolo Gelain \\ European Central Bank \\ Norges Bank \\ Kevin J. Lansing \\ Federal Reserve Bank of San Francisco \\ Gisle J. Natvik \\ BI Norwegian Business School
}

February 2018

Working Paper 2015-02

http://www.frbsf.org/economic-research/publications/working-papers/2015/02/

\section{Suggested citation:}

Gelain, Paolo, Kevin J. Lansing and Gisle J.Natvik. 2018. "Explaining the Boom-Bust Cycle in the U.S. Housing Market: A Reverse-Engineering Approach.” Federal Reserve Bank of San Francisco Working Paper 2015-02. https://doi.org/10.24148/wp2015-02

The views in this paper are solely the responsibility of the authors and should not be interpreted as reflecting the views of the Federal Reserve Bank of San Francisco or the Board of Governors of the Federal Reserve System. 


\title{
Explaining the Boom-Bust Cycle in the U.S. Housing Market: A Reverse-Engineering Approach*
}

\author{
Paolo Gelain ${ }^{\dagger} \quad$ Kevin J. Lansing Gisle J. Natvik $^{\S}$
}

February 23, 2018

\begin{abstract}
We use a quantitative asset pricing model to "reverse-engineer" the sequences of shocks to housing demand and lending standards needed to replicate the boom-bust patterns in U.S. housing value and mortgage debt from 1993 to 2015. Conditional on the observed paths for U.S. real consumption growth, the real mortgage interest rate, and the supply of residential fixed assets, a specification with random walk expectations outperforms one with rational expectations in plausibly matching the patterns in the data. Counterfactual simulations show that shocks to housing demand, housing supply, and lending standards were important, but movements in the mortgage interest rate were not.
\end{abstract}

Keywords: Housing booms, Asset price bubbles, Mortgage debt, Borrowing constraints, Lending standards, Macroprudential policy.

JEL Classification: D84, E32, E44, G12, O40, R31.

${ }^{*}$ Forthcoming in Journal of Money, Credit, and Banking. Any opinions expressed here do not necessarily reflect the views of the managements of the Federal Reserve Bank of Cleveland, the Federal Reserve Bank of San Francisco, or the Board of Governors of the Federal Reserve System. For helpful comments and suggestions, we thank Clemens Kool, Enisse Kharroubi, Kirdan Lees, Jaime Luque, Mathis Mæhlum, John Muellbauer, Paul Shea, Roman Šustek, and numerous seminar and conference participants. Part of this research was conducted while Lansing was a visiting economist at Norges Bank, whose hospitality is gratefully acknowledged.

${ }^{\dagger}$ Federal Reserve Bank of Cleveland, paolo.gelain@clev.frb.org

${ }^{\ddagger}$ Corresponding author. Federal Reserve Bank of San Francisco, kevin.j.lansing@sf.frb.org

${ }^{\S}$ BI Norwegian Business School, gisle.j.natvik@bi.no 


\section{Introduction}

Starting around the mid-1990s, the U.S. economy experienced correlated booms and busts in household real estate value, household mortgage debt, and personal consumption expenditures, as shown in Figure 1. The ratio of housing value to consumption peaked in 2006.Q1, seven quarters prior to the start of the Great Recession in 2007.Q4. The ratio of mortgage debt to consumption peaked somewhat later in 2009.Q1. The ratio of personal consumption expenditures to personal disposable income peaked in 2005.Q3. Throughout this period, the ratio of imputed housing rent to consumption declined steadily. ${ }^{1}$ Given that rents are a measure of the "dividend" or service flow from housing, the quiet behavior of rents during the boom lends support to non-fundamental explanations of the episode. Our aim is to develop a transparent quantitative model that can account for the patterns observed in Figure 1. In so doing, we assess the plausibility of the driving forces that are needed to make the model fit the data.

A wide variety of empirical evidence links the U.S. housing boom to relaxed lending standards. $^{2}$ The report of the U.S. Financial Crisis Inquiry Commission (2011) emphasizes the effects of a self-reinforcing feedback loop in which an influx of new homebuyers with access to easy mortgage credit helped fuel an excessive run-up in house prices. The run-up, in turn, encouraged lenders to ease credit further on the assumption that house prices would continue to rise. As house prices rose, the lending industry marketed a range of exotic mortgage products, e.g., loans requiring no down payment or documentation of income, monthly payments for interest-only or less, and adjustable rate mortgages with low introductory "teaser" rates that reset higher over time. Within the United States, house prices rose faster in areas where subprime and exotic mortgages were more prevalent (Mian and Sufi 2009, Pavlov and Wachter 2011, Berkovec, Chang, and McManus 2012). In a given area, past house price appreciation had a significant positive influence on subsequent loan approval rates in the same area (Dell'Ariccia, Igan, and Laeven 2012, Goetzmann, Peng, and Yen 2012).

In the aftermath of the 2001 recession, the Federal Reserve reduced the federal funds rate to just $1 \%$ and held it there for over 12 months during 2003 and 2004 . While some studies find evidence that low interest rates were an important contributor to the run-up in house prices (Taylor 2007, McDonald and Stokes 2011) others argue that low interest rates were not a major factor (Dokko, et al. 2011, Glaeser, Gottlieb, and Gyourko 2013). Aside from the possible effect on house prices, there is clear evidence that low mortgage interest rates during this period set off a refinancing boom, allowing consumers to tap the equity in their homes to pay for all kinds of goods and services. According to data compiled by Greenspan and Kennedy

\footnotetext{
${ }^{1}$ Data on household real estate value and household mortgage debt are from the Federal Reserve's Flow of Funds Accounts. Data on personal consumption expenditures and personal disposable income are from the Federal Reserve Bank of St. Louis' FRED data base. Data on imputed rents from owner-occupied housing are from www.lincolninst.edu, as documented in Davis, Lehnert, and Martin (2008).

${ }^{2}$ See, for example, Demyanyk and Van Hemert (2011), Duca, Muellbauer, and Murphy (2010, 2011), and Dokko, et al. (2011).
} 
(2008, p. 131), free cash generated by home equity extraction contributed an average of $\$ 136$ billion per year in personal consumption expenditures from 2001 to 2006 - more than triple the average yearly contribution of $\$ 44$ billion from 1996 to 2000. A follow-up analysis by Dudley (2017) finds that "between 2004 and 2006, households were increasing their cash flow by over $\$ 200$ billion a year by borrowing against their housing equity collateral." A study by Bhutta and Keys (2016) estimates that U.S. home equity extraction totaled nearly $\$ 1$ trillion from 2002 to 2005. Kermani (2012) finds that U.S. counties that experienced the largest increases in house prices from 2000 to 2006 also tended to experience the largest increases in auto sales over the same period. The same counties tended to suffer the largest declines in auto sales from 2006 to 2009 when house prices were falling. ${ }^{3}$ Similarly, Mian and Sufi (2014) identify a significant effect on auto spending that operates through home equity borrowing during the period 2002 to 2006. Laibson and Mollerstrom (2010) argue that the U.S. consumption boom from 1996 to 2006 was driven mainly by bubbly movements in house prices, not lower real interest rates.

In this paper, we use a simple quantitative asset pricing model to "reverse-engineer" the sequences of stochastic shocks that are needed to match the boom-bust patterns observed in Figure 1. We consider two versions of the model that differ according to the way that household expectations are formed, either rational expectations or random walk expectations. Conditional on the observed paths for U.S. real consumption growth, the real mortgage interest rate, and the stock of residential fixed assets, we use each model's equilibrium decision rules to back out sequences for: (1) a shock to housing preferences, and (2) a shock to lending standards (as measured by a loan-to-value limit) so as to exactly replicate the boom-bust patterns in household real estate value and mortgage debt from 1993 to 2015, as plotted in the top panels of Figure 1. We also examine the model predictions for the evolution of other variables, such as the rent-to-consumption ratio and the consumption-to-income ratio.

Under rational expectations, we show that the model requires large and persistent shocks to housing preference (i.e., housing demand shocks) to account for the boom-bust cycle in U.S. housing value. According to the model, an increase in housing preference will increase the housing service flow, as measured by the imputed rent from owner-occupied housing. Consequently, the rational expectations model predicts a similar boom-bust cycle in the rentto-consumption ratio. But this did not happen in the data.

As an alternative to rational expectations, we consider a setup where households employ simple random walk forecast rules. This type of forecast rule is consistent with a wide variety of survey evidence that directly measures agents' expectations (Case, Shiller, and Thompson 2012, Coibion and Gorodnichencko 2015). We show that the model with random walk expectations can match the boom-bust cycle in U.S. housing value with much smaller movements in the housing preference shock. With random walk expectations, the standard deviation of

\footnotetext{
${ }^{3}$ A similar pattern can be found in cross-country data on house prices and consumption. See Glick and Lansing (2010) and International Monetary Fund (2012).
} 
the housing preference variable is only about one-fourth as large as the value needed in the rational expectations model. This is because a random walk forecast exhibits a unit root which serves to magnify asset price volatility in response to shocks. ${ }^{4}$ We show that the random walk model does a much better job of matching the quiet behavior of the U.S. rent-to-consumption ratio plotted in the lower left panel of Figure 1. More generally, the random walk model captures the idea that much of the run-up in U.S. house prices and credit during the boom years appears to be linked to an influx of unsophisticated homebuyers. Given their inexperience, these buyers would be more likely to employ simple backward-looking forecast rules for future house prices, interest rates, lending standards, etc. One can also make the case that many U.S. lenders behaved similarly by approving subprime and exotic mortgage loans that could only be repaid if housing values remained high. ${ }^{5}$

New mortgage borrowing in the model is governed by a collateral constraint that depends on the market value of the housing stock. Each period, a fraction of the outstanding mortgage debt is refinanced and replaced with a new mortgage loan. The size of the new loan is subject to a collateral constraint that includes a variable that measures the strength of lending standards. For the remaining fraction of debt that is not refinanced, the borrower continues to make payments of interest and principal. The amortization rate on the mortgage contract is calibrated to approximate a conventional 30-year mortgage loan. A sustained period of rising housing value together with progressively relaxed lending standards leads to an increase in the value of new mortgage loans, contributing to a buildup in household leverage. A rapid decline in housing value leads to a rapid decline in the value of new mortgage loans, but the stock of outstanding mortgage debt declines slowly, as in the data. Using impulse response functions, we show that our setup exhibits the feature that housing value peaks earlier than mortgage debt, consistent with the data plotted in Figure 1.

When we undertake the reverse-engineering exercise, the shifts in lending standards implied by the rational expectations model are identical to those implied by the random walk model. This is because both models already match the observed time path of U.S. housing value by means of the housing preference shocks. The reverse-engineering exercise identifies a relaxation of lending standards during the boom years of 2001 to 2005 followed by a period of progressively tightening lending standards. This pattern is consistent with evidence from the Federal Reserve's Senior Loan Officer Opinion Survey on Bank Lending Practices (SLOOS) which shows that banks started to tighten lending standards before the onset of the Great Recession and often continued to tighten standards even after the recession ended.

Given the reverse-engineered shocks, both expectations models deliver the same paths for

\footnotetext{
${ }^{4}$ This mechanism for magnifying the volatility of house prices is also employed by Gelain, Lansing, and Mendicino (2013) and Gelain and Lansing (2014). But these papers do not seek to exactly replicate the boombust patterns in the U.S. data, as we do here.

${ }^{5}$ According to the report of the U.S. Financial Crisis Inquiry Commission (2011, p. 70), new subprime mortgage originations went from $\$ 100$ billion in the year 2000 to around $\$ 650$ billion at the peak in 2006 . In that year, subprime mortgages represented $23.5 \%$ of all new mortgages originated. The same report (p. 165) states: "Overall, by 2006, no-doc or low-doc loans made up $27 \%$ of all mortgages originated."
} 
the consumption-to-income ratio. According to the simple household budget constraint, the consumption-to-income ratio is driven by movements in the debt-to-consumption ratio, the mortgage interest rate, and the stock of housing which, by construction, are the same for both models. We show that the model-implied path for the consumption-to-income ratio roughly resembles the hump-shaped pattern observed in the U.S. data from 1993 to 2015.

A virtue of our approach is that we can construct counterfactual scenarios by shutting off one shock at a time while leaving the other shocks unchanged. A large gap between the model counterfactual path and the U.S. data path implies that the omitted shock plays an important role in allowing the model to match the data. While the housing preference shock plays an important role in both models, the standard deviation of the shock is much smaller in the random walk model. When we shut off the lending standard shock, the models exhibit only mild run-ups in debt. This result indicates that shifting lending standards were an important driver of the boom-bust episode. Put another way, the amplitude of the boom-bust episode might have been mitigated if mortgage regulators had been more vigilant in enforcing prudent lending standards. Shutting off the housing supply shock leads to a larger boom in the random walk model, but there is not much effect in the rational model. This is because the rational model's large housing preference shocks tend to dominate the effects of the housing supply shocks. When the mortgage interest rate shock is shut off, both models continue to match the boom-bust patterns in U.S. data, implying that the decline in the quarterly real mortgage interest rate was not an important driver of the episode. Intuitively, the mortgage interest rate decline observed in the data is not sufficient to appreciably alter the trajectories of housing value and mortgage debt in the presence of the other shocks.

Overall, our results lend support to the view that the U.S. housing boom was a classic speculative bubble involving naive projections about future asset values, imprudent lending against risky collateral, and ineffective regulatory oversight.

\subsection{Related Literature}

A common feature of all bubbles is the emergence of seemingly-plausible fundamental arguments that seek to justify the dramatic rise in asset prices. During the boom years of the U.S. housing market, many economists and policymakers argued that a bubble did not exist and that numerous fundamental factors were driving the run-ups in housing values and mortgage debt. ${ }^{6}$ Commenting on the rapid growth in subprime mortgage lending, Fed Chairman Alan Greenspan (2005) offered the view that the lending industry had been dramatically transformed by advances in information technology: "Where once more-marginal applicants would simply have been denied credit, lenders are now able to quite efficiently judge the risk posed by individual applicants and to price that risk appropriately." In a July 1, 2005 interview on the CNBC network, Ben Bernanke, then Chairman of the President's Council of Economic

\footnotetext{
${ }^{6}$ See, for example, McCarthy and Peach (2004) and Himmelberg, Mayer, and Sinai (2005).
} 
Advisers, asserted that fundamental factors such as strong growth in jobs and incomes, low mortgage rates, demographics, and restricted supply were supporting U.S. house prices. In the same interview, Bernanke stated his view that a substantial nationwide decline in house prices was "a pretty unlikely possibility."

Considering the possibility of departures from rational expectations is justified by empirical evidence from surveys that seek to directly measure investor expectations. In a review of the time series evidence on housing investor expectations from 2002 to 2008, Case, Shiller, and Thompson (2012, p. 282) find that "1-year expectations [of future house prices changes] are fairly well described as attenuated versions of lagged actual 1-year price changes." Studies by Greenwood and Shleifer (2014) and Adam, Marcet, and Beutel (2017) show that measures of investor expectations about future stock returns are strongly correlated with past stock returns and the price-dividend ratio. Koijen, Schmeling, and Vrugt (2015) find similar evidence in other assets classes, including global equities, currencies, and global fixed income investments. Jurgilas and Lansing (2013) show that the balance of households in Norway and Sweden expecting a house price increase over the next year is strongly correlated with nominal house price growth over the preceding year. Ling, Ooi, and Te (2015) find that past house price changes help to predict future house price changes even after taking into account every conceivable fundamental variable that the theory says should matter. In a study of data from the Michigan Survey of Consumers, Piazzesi and Schneider (2009, p. 407) report that "starting in 2004, more and more households became optimistic after having watched house prices increase for several years." Along these lines, Burnside, Eichenbaum, and Rebelo (2016) develop a model where agents' optimistic beliefs about future house prices can spread like an infectious disease.

Numerous recent studies have employed quantitative theoretical models to try to replicate various aspects of the boom-bust cycle in the U.S. housing market. Most of these studies preempt bubble explanations by assuming that all agents are fully rational. For example, taking the observed paths of U.S. house prices, aggregate income, and interest rates as given, Chen, Michaux, and Roussanov (2013) show that a model with rational expectations and longterm (interest-only) mortgages can approximate the observed patterns in U.S. household debt and consumption. Their quantitative exercise is similar in spirit to ours with the important exception that they do not attempt to explain movements in U.S. house prices.

Favilukis, Ludvigson, and Van Nieuwerburgh (2017) argue that the run-up in U.S. house prices relative to rents was largely due to a financial market liberalization that reduced buyers' perception of the riskiness of housing purchases, thus lowering the rational expected housing return and driving up the fundamental price-to-rent ratio. However, this mechanism is directly at odds with the survey evidence noted above which finds that investors' expected returns are high when valuation ratios are high. Even though higher valuation ratios in the data empirically predict lower realized returns, the survey evidence shows that investors fail to take this relationship into account; instead they continue to forecast high future returns following 
sustained run-ups in valuation ratios.

Standard dynamic stochastic general equilibrium (DSGE) models with fully-rational expectations have difficulty producing large swings in housing values that resemble the patterns observed in the data. It is common for such models to employ extremely large and persistent exogenous shocks to rational agents' preferences for housing in an effort to bridge the gap between the model and the data. ${ }^{7}$ We obtain a similar result here when we impose rational expectations. But, as noted above, large housing preference shocks are not a plausible explanation for the boom-bust episode because these shocks generate extremely large movements in the imputed housing rent, which are counterfactual. We show that households' use of random walk forecast rules serves to shrink substantially the required magnitude of the housing preference shocks that are needed to match the data. Our approach to increasing the volatility of the model asset price via agents' expectations is similar to other examples in the literature where agents in the model employ extrapolative-type forecast rules (Barsky and De Long 1993, Lansing 2006, 2010, Granziera and Kozicki 2015, Glaeser and Nathanson 2018).

Justiniano, Primiceri, and Tambalotti (2017) develop a stylized model that distinguishes between a credit supply constraint and the more conventional borrowing constraint. They argue that the U.S. housing boom is best explained as a relaxation of the credit supply constraint, as this reduces mortgage interest rates and thereby can generate a sizeable increase in the steady-state house price. In their quantitative exercises, they compare sequences of steady states, where each movement in the credit supply limit "is unanticipated by the agents." Hence, their proposed explanation can be interpreted as departing from rational expectations, as is done here. In contrast to their approach, our simulations account for the model's out-ofsteady-state transition dynamics. We find that the observed decline in the U.S. real mortgage interest was not an important contributor to the run-up in U.S. housing value - consistent with the empirical findings of Dokko, et al. (2011) and Glaeser, Gottlieb, and Gyourko (2013). In this regard, it's worth noting that U.S. real mortgage interest rates continued to decline for several years after 2007 while housing values also continued to fall. Our model ascribes a key role to relaxed borrowing constraints, consistent with the empirical evidence on the rapid growth of subprime mortgage lending during the boom years.

Boz and Mendoza (2014) show that a model with Bayesian learning about a regime shifting loan-to-value limit can produce a pronounced run-up in credit and land prices followed by a sharp and sudden drop. The one-period debt contract in their model causes credit and the land price to move in tandem on the downside - a feature that is not consistent with the gradual deleveraging observed in the data. Using a model that abstracts from shifts in lending standards, Adam, Kuang, and Marcet (2012) show that the introduction of constantgain learning can help account for cross-country patterns in house prices and current account dynamics.

Garriga, Manuelli, and Peralta-Alva (2017) develop a model of house price swings that

\footnotetext{
${ }^{7}$ See for example, Iacoviello and Neri (2010) and Justiniano, Primiceri, and Tambalotti (2015), among others.
} 
shares some common features with ours, i.e., long-term mortgage debt with shocks to the mortgage interest rate and lending standards. Under perfect foresight, their model cannot explain the U.S. house price boom-bust episode. In contrast, a version with "shocks to expectations" does a much better job of fitting the data. Gete (2017) shows that introducing the backward-looking survey expectations from Case, Shiller, and Thompson (2012) into a DSGE model with housing can help account for movements in U.S. house prices over the period 1994 to 2012.

\section{Model}

Housing services are priced using a version of the frictionless pure exchange model of Lucas (1978). The representative household's problem is to choose sequences of $c_{t}, h_{t}$, and $b_{t+1}$ to maximize

$$
\widehat{E}_{0} \sum_{t=0}^{\infty} \beta^{t}\left\{\log \left(c_{t}-\kappa C_{t-1}\right)+\theta_{t} \log \left(h_{t}\right)\right\},
$$

subject to the following equations

$$
\begin{aligned}
& c_{t}+p_{t}\left(h_{t}-h_{t-1}\right)+\left[r_{t}+\mu+(1-\mu) \delta\right] b_{t}=y_{t}+\mu \ell_{t} . \\
& \ell_{t} \leq m_{t} p_{t} h_{t} \\
& b_{t+1}=\mu \ell_{t}+(1-\mu)(1-\delta) b_{t}
\end{aligned}
$$

where $\beta$ is the subjective time discount factor, $\kappa$ is a parameter that influences risk aversion, and $\theta_{t} \geq 0$ is a variable that measures the strength of housing preference. The symbol $\widehat{E}_{t}$ represents the household's subjective expectation, conditional on information available at

time $t$. Under rational expectations, $\widehat{E}_{t}$ corresponds to the mathematical expectation operator $E_{t}$ evaluated using the objective distribution of shocks, which are assumed known to the rational household. The variable $c_{t}$ is real non-housing consumption and $C_{t-1}$ is lagged aggregate consumption per household, which serves as an external habit level of consumption. In equilibrium, we have $C_{t-1}=c_{t-1}$. The variable $h_{t}$ is housing consumption which is directly proportional to the stock of housing assets, $p_{t}$ is the price of the housing asset which the household takes as given, $b_{t}$ is outstanding real mortgage debt, $r_{t}$ is the real mortgage interest rate, $y_{t}$ is real disposable income, and $\ell_{t}$ is the flow of new mortgage borrowing.

We postulate that each period, the representative household faces a constant probability $\mu$ of refinancing the existing mortgage with a new loan. The size of the new loan $\ell_{t}$ is subject to a standard collateral constraint (3), where $m_{t}$ is a variable that governs the strength of lending standards. We interpret an increase in $m_{t}$ to represent a relaxation of lending standards while a decrease in $m_{t}$ is a tightening of standards. With probability $1-\mu$, the representative household continues to pay interest and principal on the existing mortgage, where $\delta \in[0,1)$ is the amortization rate, i.e., the fraction of outstanding mortgage debt that is repaid during the period. The stock of mortgage debt evolves according to the law of motion (4). When 
$\mu=1$, equations (2) through (4) imply that the entire stock of mortgage debt is refinanced each period, which is obviously not realistic. In the quantitative analysis, we set $\mu \in(0,1)$ which allows the stock of mortgage debt to exhibit inertia in response to fundamental shocks. ${ }^{8}$

The exogenous driving variables $\theta_{t}, m_{t}, R_{t} \equiv 1+r_{t}$, and $x_{t} \equiv \log \left(c_{t} / c_{t-1}\right)$ evolve according to the following laws of motion:

$$
\begin{array}{rlrlrl}
\theta_{t} & =\theta \exp \left(u_{t}\right), \quad u_{t}=\rho_{u} u_{t-1}+\varepsilon_{u, t}, & & \varepsilon_{u, t} \sim \operatorname{NID}\left(0, \sigma_{u}^{2}\right), \\
m_{t} & =m \exp \left(v_{t}\right), \quad v_{t}=\rho_{v} v_{t-1}+\varepsilon_{v, t}, & & \varepsilon_{v, t} \sim \operatorname{NID}\left(0, \sigma_{v}^{2}\right), \\
R_{t} & =R \exp \left(\tau_{t}\right), & \tau_{t}=\rho_{\tau} \tau_{t-1}+\varepsilon_{\tau, t}, & & \varepsilon_{\tau, t} \sim N I D\left(0, \sigma_{\tau}^{2}\right), \\
x_{t} & =\bar{x}+\rho_{x}\left(x_{t-1}-\bar{x}\right)+\varepsilon_{x, t}, & & \varepsilon_{x, t} \sim N I D\left(0, \sigma_{x}^{2}\right),
\end{array}
$$

where the stochastic innovations are normally and independently distributed (NID) with mean zero.

We postulate that the supply of housing responds positively to movements in the market value of housing according to the following supply function

$$
\begin{aligned}
H_{t+1} & =A H_{t}^{1-\psi}\left(p_{t} H_{t} / C_{t}\right)^{\psi} \exp \left(s_{t+1}\right), \\
s_{t} & =\rho_{s} s_{t-1}+\varepsilon_{s, t} \quad \varepsilon_{s, t} \sim \operatorname{NID}\left(0, \sigma_{s}^{2}\right),
\end{aligned}
$$

where $A>0, \psi>0$, and $H_{t}$ and $C_{t}$ are aggregate per capita variables that are viewed as outside the control of an individual household. In equilibrium, we have $H_{t}=h_{t}$ and $C_{t}=c_{t}$ for all $t$. The variable $s_{t}$ is an exogenous housing supply shock that evolves according to the law of motion (10).

Figure 2 provides empirical support for our housing supply function. Using data from the Bureau of Economic Analysis (BEA), real per capita residential investment (top left panel) exhibits a boom-bust pattern that looks very similar to the boom-bust pattern in real per capita household real estate value (bottom left panel). The top right panel of Figure 2 plots a chain-type quantity index for the net stock of private residential fixed assets, where the data is normalized to 1.0 in 1993.Q1. ${ }^{9}$ The quantity index increased by about 25\% from 1993.Q1 to its peak value in 2007.Q4. We use the BEA residential fixed asset data going back to 1960 to estimate the elasticity parameter $\psi$ in equation (9). The residuals from the regression, plotted in the bottom right panel of Figure 2, provide us with an empirical measure of the housing supply shocks. ${ }^{10}$

\footnotetext{
${ }^{8}$ The $\mu=1$ case corresponds to the setup in Iacoviello (2005), Iacoviello and Neri (2010), Adam, Kuang, and Marcet (2012), and Boz and Mendoza (2014). The $\mu \in(0,1)$ case is similar to the setup in Iacoviello (2015), Alpanda and Zubairy (2017), and Gelain, Lansing, and Natvik (2018).

${ }^{9}$ The BEA private residential fixed asset data are from NIPA Table 5.2, line 2, The corresponding investment data are from NIPA Table 5.8, Line 2. The data are available at annual frequency. We create quarterly time series by log-linear interpolation of the annual data.

${ }^{10}$ Our housing supply function $(9)$ implies that $H_{t}$ is a stationary variable whereas the quantity index in the data may exhibit a unit root. The estimated value $\psi=0.0092$ implies that $H_{t}$ in the model is highly persistent, allowing our specification to exactly replicate the path of the quantity index in the data with the appropriate sequence of housing supply shocks.
} 
The representative household's optimization problem can be formulated as

$$
\max _{c_{t}, h_{t}, b_{t+1}} \widehat{E}_{0} \sum_{t=0}^{\infty} \beta^{t} £_{t},
$$

where the current-period Lagrangian $£_{t}$ is given by

$$
\begin{gathered}
£_{t}=\log \left(c_{t}-\kappa C_{t-1}\right)+\theta_{t} \log \left(h_{t}\right)+\lambda_{t}\left[y_{t}+p_{t}\left(h_{t-1}-h_{t}\right)+b_{t+1}-R_{t} b_{t}-c_{t}\right] \\
+\lambda_{t} \eta_{t}\left[\mu m_{t} p_{t} h_{t}+(1-\mu)(1-\delta) b_{t}-b_{t+1}\right] .
\end{gathered}
$$

The variables $\lambda_{t}$ and $\eta_{t}$ are Lagrange multipliers and we have used equation (4) to eliminate the term $\mu \ell_{t}$ from the household budget constraint (2).

The household's first-order conditions with respect to $c_{t}, h_{t}$, and $b_{t+1}$ are given by

$$
\begin{aligned}
\lambda_{t} & =\frac{1}{c_{t}\left[1-\kappa \exp \left(-x_{t}\right)\right]} \\
\lambda_{t} p_{t} & =\frac{\theta_{t}}{h_{t}}+\lambda_{t} \eta_{t} \mu m_{t} p_{t}+\beta \widehat{E}_{t} \lambda_{t+1} p_{t+1}, \\
\lambda_{t} \eta_{t} & =\lambda_{t}-\beta \widehat{E}_{t} \lambda_{t+1}\left[R_{t+1}-(1-\mu)(1-\delta) \eta_{t+1}\right],
\end{aligned}
$$

where we have imposed $C_{t-1}=c_{t-1}$ and $c_{t-1} / c_{t}=\exp \left(-x_{t}\right)$ in equation (13). After dividing both sides of equation (14) by $\lambda_{t}$, we can see that the "dividend" or imputed rent from owneroccupied housing is given by $\theta_{t} /\left(\lambda_{t} h_{t}\right)+\eta_{t} \mu m_{t} p_{t}$. The imputed rent consists of two parts: (1) a service flow per unit of housing that is influenced by the stochastic preference variable $\theta_{t}$, and (2) the marginal collateral value of the house in the case when the borrowing constraint is binding, i.e., when $\eta_{t}>0 .{ }^{11}$ Equation (14) also shows that, all else equal, an increase in the equilibrium housing supply $h_{t}$ will put downward pressure on the house price $p_{t}$.

\subsection{Rational Expectations}

In Appendix A, we express the model equilibrium conditions in terms of the stationary variables $p_{n, t} \equiv p_{t} h_{t} / c_{t}, b_{n, t} \equiv b_{t} / c_{t-1}$, and $b_{n, t+1} \equiv b_{t+1} / c_{t}$. This procedure facilitates a log-linear approximate solution of the model in the vicinity of the steady state. Details of the rational expectations solution are contained in Appendix B. The decision variables are $p_{n, t}, b_{n, t+1}$, and $\eta_{t}$. The seven state variables are: (1) the normalized stock of mortgage debt $b_{n, t}$, (2) the equilibrium housing stock $h_{t}$, (3) the housing preference shock $u_{t}$, (4) the lending standard shock $v_{t},(5)$ the mortgage interest rate shock $\tau_{t},(6)$ the housing supply shock $s_{t}$, and $(7)$ the consumption growth rate $x_{t}$.

\footnotetext{
${ }^{11}$ We confirm that the borrowing constraint is binding at the model steady state. As is common in the literature, we solve the model assuming that the borrowing constraint is always binding in a neighborhood around the steady state.
} 


\subsection{Random Walk Expectations}

The rational expectations solution is based on strong assumptions about the representative household's information set. Specifically, the rational solution assumes that the household knows the stochastic processes for all five exogenous shocks. The survey evidence described in Section 1.1 shows that there is strong empirical support for backward-looking type forecast rules. Motivated by the survey evidence, we postulate that the representative household employs simple random walk forecast rules that require only a minimal amount of computational and informational resources. As noted by Nerlove (1983, p. 1255), "Purposeful economic agents have incentives to eliminate errors up to a point justified by the costs of obtaining the information necessary to do so... The most readily available and least costly information about the future value of a variable is its past value."

From the transformed equilibrium conditions in Appendix A, we see that two of the variables that the agent must forecast are $p_{n, t+1} \equiv p_{t+1} h_{t+1} / c_{t+1}$ and $R_{t+1} \equiv 1+r_{t+1}$. Figure 3 examines the suitability of a random walk forecast to predict these variables in U.S. data. The figure plots the root mean squared percentage forecast error (RMSPFE) for one-quarter ahead forecasts using a forecast rule of the form $\widehat{E}_{t} z_{t+1}=\omega z_{t}+(1-\omega) \widehat{E}_{t-1} z_{t}$, where $z_{t+1} \in\left\{p_{n, t+1}, R_{t+1}\right\}$. The parameter $\omega>0$ governs the weight assigned to the most recent observation - analogous to the Kalman gain in a model with noisy information, along the lines of Coibion and Gordonichenko (2015). For the variable $p_{n, t+1}$, forecast performance is best (lowest RMSPFE) when $\omega \simeq 1.1$ for the pre-boom period and $\omega \simeq 1.7$ for the boom-bust period. For the variable $R_{t+1}$, forecast performance is best when $\omega \simeq 1.3$ during both periods. When $\omega>1$, a positive forecast error in the current period leads to an upward adjustment in the forecasted growth of the variable in the next period. ${ }^{12}$ The value $\omega=1$ corresponds to a random walk forecast. Both panels of Figure 3 shows that a forecast rule with $\omega=1$ does not sacrifice much in terms forecast performance relative to higher values of $\omega$. Details of the model solution using random walk expectations are contained in Appendix C.

\section{Parameter Values}

Tables 1 and 2 show the values of the model parameters that we employ in the simulations. The parameter values in Table 1 are the same for both expectation models. The habit formation parameter $\kappa$ is set to achieve a coefficient of relative risk aversion approximately equal to 2 in steady state. The steady state coefficient of relative risk aversion is given by $1 /[1-\kappa \exp (\bar{x})]$, where $\bar{x}$ is the steady state consumption growth rate. We also experimented with alternative values of $\kappa$, as high as 0.9 . The results were broadly similar to the case when $\kappa=0.5$. This is because the volatility of U.S. consumption growth is relatively low and therefore does not induce large swings in the model-implied risk aversion coefficient during the simulations.

\footnotetext{
${ }^{12}$ To see this, the forecast rule can be rearranged as follows: $\widehat{E}_{t}\left(z_{t+1}-z_{t}\right)=(\omega-1)\left[z_{t}-\widehat{E}_{t-1} z_{t}\right]$.
} 
Table 1: Model Parameter Values

\begin{tabular}{ccl}
\hline \hline Parameter & Value & \multicolumn{1}{c}{ Description/Target } \\
\hline$\kappa$ & 0.5 & Steady state risk aversion coefficient $\simeq 2$. \\
$m$ & 0.86 & LTV of first-time homebuyers $=0.86$ in 1993.Q1 \\
$\beta$ & 0.9876 & Housing value/quarterly consumption = 7.3 in 1993.Q1 \\
$\theta$ & 0.1596 & House price/quarterly rent = 80.6 in 1993.Q1 \\
$\mu$ & 0.0164 & Mortgage debt/quarterly consumption = 2.6 in 1993.Q1 \\
$R$ & 1.012 & Gross quarterly real mortgage interest rate in 1993.Q1. \\
$\bar{x}$ & 0.0045 & Average quarterly real per capita consumption growth. \\
$\delta$ & 0.019 & Approximate 30-year mortgage amortization rate. \\
$\psi$ & 0.0092 & Estimated from BEA private residential fixed assets. \\
$A$ & 0.9819 & Consistent with model steady state in 1993.Q1. \\
\hline
\end{tabular}

From the collateral constraint (3), the parameter $m$ represents the loan-to-value (LTV) ratio of a new mortgage loan in the event that the household refinances the existing loan. We choose $m=0.86$ to approximate the average LTV of U.S. first-time homebuyers in 1993.Q1, as plotted by Duca, Muellbauer, and Murphy (2011, p. 534).

From Figure 1, we see that the U.S. housing market ratios are all close to their long-run means in 1993.Q1. The two expectations models share the same steady state. We choose the values of $\beta, \theta$, and $\mu$ simultaneously so that the following steady state model ratios are equal to the corresponding U.S. ratios in 1993.Q1: (1) house price-to-rent, (2) housing value-to-consumption, and (3) mortgage debt-to-consumption. Data on median U.S. house prices and median imputed rents from owner-occupied housing are from the Lincoln Land Institute. ${ }^{13}$ For consistency with the model, the house price and rent series are both scaled (preserving the price-to-rent ratio) so that the ratio of the median house price to per capita U.S. consumption in 1993.Q1 coincides with the ratio of aggregate U.S. housing value to aggregate U.S. consumption in the same quarter, implying a normalized housing stock of $h_{t}=1$ in 1993.Q1. Data on U.S. residential real estate values and household mortgage debt are from the Federal Reserve's Flow of Funds. Data on real personal consumption expenditures and population are from the Federal Reserve Bank of St. Louis' FRED database.

The variable $R_{t}$ in the model is the gross quarterly real mortgage interest rate which we construct from the data. ${ }^{14}$ The steady state value $R=1.012$ corresponds to the observed value in 1993.Q1. Given the high volatility of real per capita consumption growth from one quarter to the next, we choose the steady state value $\bar{x}$ to coincide with the sample average from 1993.Q1 to 2015.Q4. We compute the parameter values $\rho_{x}, \sigma_{x}, \rho_{\tau}$, and $\sigma_{\tau}$ to match the persistence and volatility properties of $x_{t}$ and $R_{t}$ in the data from 1993.Q1 to 2015.Q4.

\footnotetext{
${ }^{13}$ See www.lincolninst.edu. For prices, we use the data series that includes the Case-Shiller-Weiss measure from the year 2000 onwards, as documented in Davis, Lehnert, and Martin (2008).

${ }^{14}$ We start with data on the nominal 30-year conventional mortgage interest rate from the Federal Reserve Bank of St. Louis' FRED database. We then convert the annualized nominal mortgage interest rate into a quarterly real rate using the trailing 12-month PCE inflation rate as a measure of expected inflation (converted to a quarterly expected inflation rate).
} 
Following Alpanda and Zubairy (2017) and Gelain, Lansing, and Natvik (2018), we choose $\delta=0.019$ to achieve a realistic amortization rate for a typical 30-year conventional mortgage. The computation is based on an approximate law of motion for the amortization rate developed by Kydland, Rupert, and Šustek (2016).

We use the BEA's chain-type quantity index for the net stock of private residential fixed assets to construct a normalized path for the real per capita U.S. housing stock from 1960 to 2015. The data are available at annual frequency, so we first create a quarterly time series by log-linear interpolation of the data. We then normalize the quarterly series so that $h_{t}=1$ in 1993.Q1 when $p_{n, t} \equiv p_{t} h_{t} / c_{t}=7.3$. Given the data for $h_{t}$ and $p_{n, t}$, we run a regression of $\log \left(h_{t+1} / h_{t}\right)$ on a constant and $\log \left(p_{n, t} / h_{t}\right)$. The estimated elasticity coefficient is $\psi=0.0092$, s.e. $=0.0008$. The residuals from the regression define the housing supply shocks which are plotted in the lower right panel of Figure 2. ${ }^{15}$ The values of the parameters $\rho_{s}$ and $\sigma_{s}$ are chosen to match the persistence and volatility properties of the housing supply shocks. Finally, we calibrate the parameter $A$ in the housing supply equation to be consistent with the model steady state at 1993.Q1.

Table 2: Parameter Values for Shocks

\begin{tabular}{cccl}
\hline \hline Parameter & RE model & RW model & \multicolumn{1}{c}{$\begin{array}{c}\text { 1993.Q1 - 2015.Q4 } \\
\text { Description/Target }\end{array}$} \\
\hline$\rho_{x}$ & 0.5625 & 0.5625 & AR(1) consumption growth rate. \\
$\sigma_{x}$ & 0.0039 & 0.0039 & Std. dev. consumption growth rate \\
$\rho_{\tau}$ & 0.9645 & 0.9645 & AR(1) mortgage interest rate. \\
$\sigma_{\tau}$ & 0.00085 & 0.00085 & Std. dev. mortgage interest rate. \\
$\rho_{s}$ & 0.9522 & 0.9522 & AR(1) housing supply shock. \\
$\sigma_{s}$ & 0.00054 & 0.00054 & Std. dev. housing supply shock. \\
$\rho_{u}$ & 0.9600 & 0.9600 & AR(1) housing preference shock. \\
$\sigma_{u}$ & 0.2071 & 0.0499 & Std. dev. housing value/consumption. \\
$\rho_{v}$ & 0.9600 & 0.9600 & AR(1) lending standard shock. \\
$\sigma_{v}$ & 0.0720 & 0.0721 & Std. dev. mortgage debt/consumption. \\
\hline
\end{tabular}

Notes: $\mathrm{RE}=$ rational expectations. $\mathrm{RW}=$ random walk expectations.

The persistence parameters for the housing preference shock $u_{t}$ and the lending standard shock $v_{t}$ are both set to 0.96 , consistent with the observed high persistence of the other two housing market shocks, namely, the mortgage interest rate shock $\tau_{t}$ and the housing supply shock $s_{t}$. We allow the standard deviations $\sigma_{u}$ and $\sigma_{v}$ to differ across the two expectation models. Specifically, we calibrate the values of $\sigma_{u}$ and $\sigma_{v}$ so that the rational expectations (RE) model and the random walk expectations (RW) model can each match the observed standard deviations of the U.S. housing ratios plotted in the top panels of Figure 1 over the period from 1993 to 2015. Analytical moment formulas derived from the log-linear solutions of both models are used in the calibration procedure.

\footnotetext{
${ }^{15}$ Lansing and Markiewicz (2018) employ a similar procedure to allow their model to exactly replicate the path of private nonresidential fixed assets in the data.
} 
From Table 2, we see that the RE model requires a highly volatile housing preference shock with $\sigma_{u}=0.2071$. This is four times larger than the corresponding value $\sigma_{u}=0.0499$ in the RW model. This comparison highlights the RW model's ability to generate excess volatility in the equilibrium house price. Conditional on matching the observed volatility of $p_{t} h_{t} / c_{t}$ in the data, both models require $\sigma_{v} \simeq 0.072$ to match the observed volatility of $b_{t} / c_{t}$.

\section{Quantitative Results}

\subsection{Simulations with Model-Specific Shocks}

Figure 4 shows simulation results for the two model versions using the parameter values in Tables 1 and 2. The four panels in Figure 4 are the model-generated versions of the corresponding U.S. data ratios plotted earlier in Figure 1. Our calibration procedure ensures that the RE model and the RW model both match the standard deviations of the housing value-to-consumption ratio and the mortgage debt-to-consumption ratio from 1993 to 2015. Consequently, the top two panels of Figure 4 exhibit very similar patterns for the two models.

A crucial distinction between the RE model and the RW model can be seen in the lower left panel of Figure 4. The RE model predicts substantially higher volatility in the rentto-consumption ratio compared to the RW model. This is because the RE model's housing preference shock has $\sigma_{u}=0.2071$ versus $\sigma_{u}=0.0499$ in the RW model. The volatility of the housing preference shock directly influences the rent-to-consumption ratio which is given by

$$
\frac{\operatorname{Rent}_{t}}{c_{t}}=\frac{\theta_{t}\left[1-\kappa \exp \left(-x_{t}\right)\right]}{h_{t}}+\frac{\eta_{t} \mu m_{t} p_{n, t}}{h_{t}}
$$

where $\theta_{t}=\theta \exp \left(u_{t}\right)$ is the stochastic housing preference variable. The first term on the right side of equation (16) is the housing service flow i.e., the utility dividend, while the second term is the marginal collateral value of the housing asset. In the simulations, the volatility of the rent-to-consumption ratio is determined mainly by movements in $\theta_{t}$.

The coefficient of variation for the rent-to-consumption ratio from a long simulation is 0.75 in the RE model versus 0.21 in the RW model. For comparison, the coefficient of variation for the rent-to-consumption ratio in U.S. data is 0.12 from 1960.Q1 to 2015.Q4. For the more-recent period of 1993.Q1 to 2015.Q4, the coefficient of variation is even lower at 0.02. The extremely low volatility of the rent-to-consumption ratio in the data argues against fundamental demand shocks as a key driver of the boom-bust episode. A virtue of the RW model is its ability to generate realistic volatility in the housing value-to-consumption ratio without the need for implausibly large housing demand shocks.

In Appendix A, we show that the normalized version of the household's budget constraint (2) can be written as follows

$$
\frac{c_{t}}{y_{t}}=\frac{1}{1+p_{n, t}\left(1-h_{t-1} / h_{t}\right)+R_{t} b_{n, t} \exp \left(-x_{t}\right)-b_{n, t+1}},
$$


where the equilibrium housing supply function implies $h_{t-1} / h_{t}=A^{-1}\left(p_{n, t-1} / h_{t-1}\right)^{-\psi} \exp \left(-s_{t}\right)$. The exogenous variables $x_{t}, R_{t}$, and $s_{t}$ are the same for both models. Our calibration procedure ensures that the standard deviations of $p_{n, t}$ and $b_{n, t}$ are the same for both models. This explains why the behavior of the consumption-to-income ratio in the simulations is nearly identical for both models, as shown in the lower right panel of Figure 4.

\subsection{Impulse Response Functions with Common Shocks}

Figure 5 shows how a common stochastic shock propagates differently in the two models. The left panels show impulse response functions for the housing value-to-consumption ratio. The right panels show impulse response functions for the mortgage debt-to-consumption ratio. From top to bottom, we show the results for a one standard deviation positive innovation to the housing preference shock $u_{t}$, the lending standard shock $v_{t}$, the interest rate shock $\tau_{t}$, and the housing supply shock $s_{t}$. The standard deviations of the shock innovations are the calibrated values from the RW model, as shown in Table 2. The vertical axes measure the percentage deviation of the variable from the deterministic steady state.

The housing value and mortgage debt ratios both increase in response to a positive housing preference shock and a positive lending standard shock. Both ratios decrease in response to a positive interest rate shock and a positive housing supply shock. The impulse response functions show that the RW model exhibits excess volatility relative to the RE model. This result is due to the household's random walk forecast rules which embed a unit root assumption. Due to the self-referential nature of the equilibrium conditions, the households' subjective forecast influences the dynamics of the object that is being forecasted. ${ }^{16}$

The effects of the shocks are temporary but highly persistent - in most cases lasting in excess of 80 quarters (20 years). Another notable feature is the timing of the peaks in housing value versus mortgage debt. Our specification with long-term mortgage debt causes the peak in housing value to occur well before the peak in debt. This is qualitatively similar to the pattern observed in Figure 1 for the U.S. data. When the entire stock of mortgage debt is refinanced each period $(\mu=1)$, both peaks occur at the same time

\subsection{Reverse-Engineering Shocks to Match the Data}

We now undertake the main part of our quantitative analysis: reverse-engineering the sequences of shocks to housing demand and lending standards that are needed to replicate the boom-bust patterns in U.S. housing value and mortgage debt from 1993 to 2015. All of the model's state variables are set equal to their deterministic steady state values at 1993.Q1. As inputs to the exercise, the model variables $x_{t}, R_{t}$, and $h_{t}$ take on the values observed in U.S.

\footnotetext{
${ }^{16}$ A simple example illustrates the point. Suppose that $p_{t}=d_{t}+\beta \widehat{E}_{t} p_{t+1}$, where $d_{t}$ follows an $\operatorname{AR}(1)$ process with persistence $\gamma$. Under rational expecations, we have $\operatorname{Var}\left(p_{t}\right) / \operatorname{Var}\left(d_{t}\right)=1 /(1-\gamma \beta)^{2}$. When $\widehat{E}_{t} p_{t+1}=p_{t}$, we have $\operatorname{Var}\left(p_{t}\right) / \operatorname{Var}\left(d_{t}\right)=1 /(1-\beta)^{2}$ which implies excess volatility in the model asset price whenever $|\gamma|<1$.
} 
data over the period 1993.Q2 to 2015.Q4. The time series for $x_{t}$ and $R_{t}-1$ are plotted in the top panels of Figure 6, while the time series for $h_{t}$ is plotted in the top right panel of Figure 2. The law of motion (7) is used to compute the values of the interest rate shock $\tau_{t}$. The time series for the housing supply shock $s_{t}$ is plotted in the lower right panel of Figure 2.

For each version of the model, we use the exact law of motion for the normalized variable $b_{n, t+1}$, equation (A.4) in Appendix A, to back out the sequence for the lending standard variable $m_{t}$ that is needed to match the path of the U.S. mortgage debt-to-consumption ratio, where the normalized variable $p_{n, t}$ is given by the U.S. housing value-to-consumption ratio and $x_{t}$ is given by the U.S. real per capita consumption growth rate. Since equation (A.4) holds exactly for both models, the resulting sequence for $m_{t}$ is the same for both models. Given the sequence for $m_{t}$, we use the law of motion (6) to compute the values of the lending standard shock $v_{t}$. Next, we use each model's log-linearized decision rule for $p_{n, t}$ to back out sequences for the housing preference shock $u_{t}$ so as to match the U.S. housing value-toconsumption ratio. Given the sequences for $u_{t}$, we use the law of motion (5) to compute the corresponding paths for the housing preference variable $\theta_{t}$. The bottom panels of Figure 6 plot the reverse-engineered paths for $\theta_{t}$ and $m_{t}$ in each model.

Analogous to the model simulations in Figure 4, the RE model requires much larger movements in $\theta_{t}$ to match the data. The standard deviation of $\theta_{t}$ is 0.188 in the RE model versus only 0.046 in the RW model. The time pattern of $\theta_{t}$ in the RE model closely mimics the path of the U.S. housing value-to-consumption ratio in Figure 1. Hence, the RE model "explains" the boom-bust cycle in U.S. housing value as an exogenous phenomenon. In contrast, the RW model requires much smaller movements in $\theta_{t}$ to match the same data.

While the flow of new mortgage borrowing $\ell_{t}$ moves in tandem with housing value according to the borrowing constraint (3), the stock of long-term mortgage debt adjusts more slowly than housing value. In order to match the rapid run-up in the stock of U.S. mortgage debt, the models require a substantial relaxation of lending standards, as summarized by the single variable $m_{t}$. The bottom right panel of Figure 6 shows that $m_{t}$ must rise from a steady state value of 0.86 in 1993.Q1 to an average value of 1.3 during the four year period from 2003 through 2006. The dramatic changes in U.S. housing finance that occurred during the boom years included the rapid growth of mortgage loans requiring little or no down payment. ${ }^{17}$ Nevertheless, the model-implied rise in $m_{t}$ should not be taken literally as a prediction for the LTV of the representative homebuyer. Rather, the rise in $m_{t}$ summarizes an overall environment of weakening lending standards. For the exercise, we hold the probability $\mu$ of refinancing the existing mortgage constant. Allowing $\mu$ to adjust upwards during the boom years would reduce the model-implied rise in $m_{t}$. This alternative would be a stylized way of capturing another feature of the U.S. housing boom, namely, the rapid growth in cash-out mortgage refinancings that helped fuel the rise in the U.S. consumption-to-income ratio.

Period-by-period fluctuations in the stock of mortgage debt in the data translate into the

\footnotetext{
${ }^{17}$ See the report of the U.S. Financial Crisis Inquiry Commission (2011), Chapter 7.
} 
need for large fluctuations in the flow of new loans, thus accounting for the high volatility of $m_{t}$. Notice that $m_{t}$ starts declining before the onset of the Great Recession in 2007.Q4. A declining value of $m_{t}$ summarizes an overall environment of tightening lending standards. After 2007.Q4, the value of $m_{t}$ is remains mostly below its steady state value.

Figure 7 plots two indicators of lending standard tightness from the Federal Reserve's Senior Loan Officer Opinion Survey on Bank Lending Practices (SLOOS). The indicators are the net percentage of U.S. domestic banks that are tightening lending standards for either residential mortgage loans or credit card loans. ${ }^{18}$ Both series show that banks started to tighten lending standards before the onset of the Great Recession. Moreover, a substantial percentage of banks continued to tighten standards even after the recession ended in 2009.Q2. Overall, the SLOOS data is qualitatively consistent with the model-implied path for $m_{t}$.

Although not shown, we also experimented by setting $\mu=1$, implying that the entire stock of mortgage debt is refinanced each period - a setup that is often used in the literature. In this case, the models do not require any significant increase in $m_{t}$ to match the run-up in U.S. mortgage debt. When $\mu=1$, the stock of debt moves in tandem with housing value. Since housing value is driven upwards by the other shocks, a significant loosening of lending standards is not needed to explain the run-up in debt. Things are different, however, during the bust years. To avoid the counterfactual prediction of a rapid deleveraging as U.S. housing values fell rapidly, the $\mu=1$ case requires a post-2007 relaxation of lending standards, i.e., an increase in $m_{t}$, to simultaneously match the patterns of housing value and mortgage debt in the data.

Figure 8 plots the model-implied paths for two other variables of interest, namely, the housing rent-to-consumption ratio, given by equation (16), and the consumption-to-income ratio, given by equation (17). The RE model predicts a counterfactual boom-bust cycle in the rent-to-consumption ratio that is driven by the large movements in the reverse-engineered housing preference variable $\theta_{t}$. In contrast, the rent-to-consumption ratio in the RW model lies much closer to the data. The endogenous bubble-like dynamics generated by household's random walk forecast rules allows the RW model to match the data with much smaller housing preference shocks, thereby avoiding the prediction of large movements in imputed housing rents.

Both models deliver identical paths for the consumption-to-income ratio. Equation (17) shows that movements in this ratio are linked mechanically to movements in the variables $p_{n, t}$, $b_{n, t}, x_{t}, R_{t}$ and $h_{t}$ which, by construction, exactly replicate the paths observed in the data. For comparison purposes, we normalize the model-predicted consumption-to-income ratio to have the same mean as the U.S. ratio from 1993 to 2015. Abstracting from high-frequency fluctuations, the model-predicted path for the consumption-to-income ratio exhibits a general

\footnotetext{
${ }^{18}$ The data are available from www.federalreserve.gov/boarddocs/SnLoanSurvey/. Prior to 2007.Q2, the survey data do not distinguish between prime and subprime mortgages. From 2007.Q2 onwards, we plot the survey responses for prime mortgages.
} 
hump-shaped pattern that is positively correlated with the boom-bust cycles in housing value and mortgage debt. This feature of the model is consistent with the empirical evidence cited in the introduction which indicates that a significant portion of the run-up in U.S. mortgage debt during the boom years was used to finance a short-term spending binge by consumers. Relative to the U.S. data, the model consumption-to-income ratio drops more severely during the Great Recession. But of course the model is missing the numerous automatic stabilizers and policy responses that helped to support U.S. consumer spending as these events transpired.

\subsection{Counterfactual Scenarios}

Our final quantitative exercise examines four counterfactual scenarios that are plotted in Figure 9. In each set of panels from top to bottom, we turn off one housing market shock at a time while leaving the other shocks in place. The purpose of the exercise is to see which housing market shocks are the most important for explaining the boom-bust episode, as viewed through the lens of each model.

In the top set of panels in Figure 9, we shut off the housing preference shock so that $\theta_{t}$ remains constant at its steady state value for all $t$. The RE model now exhibits no significant run-up in housing value. This result confirms the importance of the housing preference shock in "explaining" the episode under rational expectations. In contrast, the RW model still exhibits a nontrivial run-up in housing value, albeit smaller in magnitude than the run-up observed in the data. But recall that the housing preference shock that we shut off in the RW model is already many times smaller than the corresponding shock in the RE model. The top right panel of Figure 9 shows that shutting off the housing preference shock serves to dampen the run-up in mortgage debt in both models relative to the U.S. data. This confirms the importance of rising housing value as a driver of mortgage credit expansion in both models.

In the second set of panels in Figure 9, we shut off the lending standard shock so that $m_{t}$ remains constant at its steady state value for all $t$. There is not much effect on housing value in either model. This is because housing value is driven mainly by the other shocks, particularly the housing preference shock. This result highlights a weakness in both models, namely, the lack of a strong feedback effect from mortgage credit expansion to subsequent housing value appreciation. An element that is missing from our framework is a mechanism whereby the weakening of lending standards during the boom years allows for an influx of new homebuyers and speculative investors who then use borrowed money to bid up house prices. In contrast to the small effect on housing value, the right panel shows that shutting off the lending standard shock serves to largely eliminate the run-up in mortgage debt in both models. According to the models, shifting lending standards were an important driver of the boom-bust episode in mortgage debt. This counterfactual scenario can be viewed as kind of a macroprudential policy experiment, i.e., what would have happened if regulators had enforced prudent lending standards during the boom years? According to the models, prudent regulatory action would have helped to restrain the mortgage lending boom such that the subsequent debt overhang 
and forced deleveraging would have been less severe.

In the third set of panels in Figure 9, we shut off the mortgage interest rate shock so that $R_{t}$ remains constant at its steady state value for all $t$. Both models continue to exhibit significant boom-bust cycles in housing value and mortgage debt. This is because the magnitude of the mortgage interest rate decline in the data is simply too small to have much impact. The top right panel of Figure 6 shows that the quarterly real mortgage interest rate in the data declined by only about 30 basis points on net during the boom years. After 2007.Q4, the quarterly real mortgage interest rate continued to decline by about 60 basis points, eventually hitting bottom in 2012.Q4. These interest rate drops are not sufficient to appreciably alter the trajectories of housing value and mortgage debt in the presence of the other shocks. Hence, according to the models, the decline in the U.S. mortgage interest rate was not a major driver of the boombust episode. Any model that attributes a large explanatory role to the mortgage interest rate drop during the boom years prior to 2007.Q4 will likely encounter difficulty explaining why the subsequent larger drop in mortgage interest rates after 2007.Q4 did not appear to support U.S. housing values.

Our result that the mortgage interest rate drop was not important conflicts with the findings of Taylor (2007) and McDonald and Stokes (2011) who argue that the Fed's decision to keep interest rates artificially low during the boom years helped fuel the housing bubble. Other studies, however, are in agreement with our result. Dokko, et al. (2011) present evidence that movements in U.S. house prices were much larger than can be explained by the historical relationship between house prices and interest rates. An empirical study by Glaeser, Gottlieb, and Gyourko (2013) finds that lower real interest rates can only explain about $20 \%$ of the rise in U.S. house prices from 1996 to 2006. One way to reconcile these various findings is to postulate that the prevailing environment of low interest rates during the boom years fostered excessive risk-taking by lenders, who relaxed lending standards in the pursuit of higher profits. Adrian and Shin (2010) and Jiménez, et al. (2014) present evidence that low interest rate environments contribute to increased risk-taking by lenders.

In the bottom set of panels in Figure 9, we shut off the housing supply shock so that $s_{t}=0$ for all $t$. From the top right panel of Figure 2, we see that shutting off the housing supply shock serves to dampen the model supply response relative to what is actually observed in the U.S. data. Shutting off the supply shock produces little effect in the RE model, which continues to closely track the U.S. data. This is because movements in the RE model are driven mainly by the large housing preference shock. In contrast, shutting off the housing supply shock in the RW model produces a larger boom in both housing value and mortgage debt. Supply shocks play a larger role in the RW model precisely because the model's smaller housing preference shocks do not dominate the effects of the supply shocks.

To quantify the relative importance of the various shocks in each model, we compute the standard deviations of the variables $p_{t} h_{t} / c_{t}$ and $b_{t} / c_{t}$ for each counterfactual scenario and then divide these statistics by the corresponding standard deviations in the baseline exercise with 
all shocks present. The results are shown in Table $3 .{ }^{19}$ A number close to 1.0 implies that the shock in question is not very important in allowing the model to match the U.S. data from 1993 to 2015. A number lower than 1.0 implies that the shock in question serves to magnify the boom-bust cycle. A number higher than 1.0 implies that the shock in question serves to dampen the boom-bust cycle.

Table 3: Ratio of Standard Deviations: Counterfactual relative to Baseline

\begin{tabular}{lcccc}
\hline \hline \multirow{2}{*}{ Counterfactual scenario } & \multicolumn{2}{c}{$p_{t} h_{t} / c_{t}$} & \multicolumn{2}{c}{$b_{t} / c_{t}$} \\
& RE model & RW model & RE model & RW model \\
\hline No housing preference shock & 0.243 & 0.783 & 0.617 & 0.729 \\
No lending standard shock & 0.969 & 0.916 & 0.457 & 0.441 \\
No interest rate shock & 0.988 & 0.976 & 0.984 & 0.947 \\
No housing supply shock & 0.961 & 1.194 & 0.964 & 1.066 \\
\hline
\end{tabular}

Notes: Each number is the standard deviation in the counterfactual scenario divided by the standard deviation in the baseline exercise with all shocks present. $\mathrm{RE}=$ rational expectations, $\mathrm{RW}=$ random walk expectations.

The quantitative results in Table 3 confirm the visual findings from Figure 9. The housing preference shock is extremely important in the RE model. When this shock is shut off, the standard deviation of $p_{t} h_{t} / c_{t}$ drops to $24 \%$ of the baseline value, while the standard deviation of $b_{t} / c_{t}$ drops to $62 \%$ of the baseline value. The corresponding numbers in the RW model are $78 \%$ and $73 \%$, respectively, confirming the smaller role played by this shock. When the lending standard shock is shut off, both models exhibit around a $45 \%$ drop in the standard deviation of $b_{t} / c_{t}$. Shutting off the interest rate shock causes the various standard deviations to drop by only $5 \%$ or less in both models. Shutting off the housing supply shock only slightly reduces the standard deviations in the RE model. But in the RW model, shutting off the housing supply shock causes the standard deviations of $p_{t} h_{t} / c_{t}$ and $b_{t} / c_{t}$ to go up by $19 \%$ and $7 \%$, respectively. Overall, the results in Table 3 show that shocks to housing demand, housing supply, and lending standards were all potentially important, but movements in the mortgage interest rate were not.

\section{Conclusion}

Episodes of explosive, bubble-like growth in house prices have occurred in many OECD countries over the past four decades (Engsted, Hviid, and Pedersen 2016). A recent cross-country empirical study by Jordà, Schularick, and Taylor (2015, p. S17) concludes that "Mortgage and house price booms are predictive of future financial crises, and this effect has also become much more dramatic since WW2." Our simple quantitative asset pricing model helps to shed

\footnotetext{
${ }^{19}$ Our methodology is conceptually similar to that of Chari, McGrattan, and Kehoe (2007) who develop a quantitative business cycle model to assess the relative importance of four "wedges" that relate to labor, investment, productivity, and government consumption.
} 
light on the underlying causes of the recent boom-bust cycle in the U.S. housing market. A clear understanding of these causes is important because it could help in the design of policy actions to avoid future crises.

The official report of the U.S. Financial Crisis Inquiry Commission (2011, p. xvii) states: "We conclude this financial crisis was avoidable... Despite the expressed view of many on Wall Street and in Washington that the crisis could not have been foreseen or avoided, there were warning signs. The tragedy was that they were ignored or discounted." The report lists such red flags as "an explosion in risky subprime lending and securitization, an unsustainable rise in housing prices, widespread reports of egregious and predatory lending practices, (and) dramatic increases in household mortgage debt."

Our preferred model of the boom-bust cycle includes the following elements: (1) households who employ simple backward-looking forecast rules that give rise to excess volatility in house prices, (2) long-term mortgage contracts that cause the stock of outstanding household debt to adjust more slowly than the flow of new loans, and (3) relaxed lending standards during the run-up that allowed for excessive household borrowing. 


\section{A Appendix: Equilibrium Conditions in Stationary Variables}

We define the following stationary variables: $p_{n, t} \equiv p_{t} h_{t} / c_{t}, b_{n, t} \equiv b_{t} / c_{t-1}$, and $b_{n, t+1} \equiv$ $b_{t+1} / c_{t}$. After substituting in these definitions, the transformed equilibrium conditions are

$$
\begin{aligned}
& p_{n, t}=\frac{1-\kappa \exp \left(-x_{t}\right)}{1-\eta_{t} \mu m_{t}}\left\{\theta_{t}+\beta \widehat{E}_{t}\left[\frac{p_{n, t+1}}{1-\kappa \exp \left(-x_{t+1}\right)}\left(h_{t} / h_{t+1}\right)\right]\right\}, \\
& \eta_{t}=1-\beta\left[1-\kappa \exp \left(-x_{t}\right)\right] \widehat{E}_{t}\left\{\frac{\exp \left(-x_{t+1}\right)}{1-\kappa \exp \left(-x_{t+1}\right)}\left[R_{t+1}-(1-\mu)(1-\delta) \eta_{t+1}\right]\right\} \\
& c_{t} / y_{t}=\left[1+p_{n, t}\left(1-h_{t-1} / h_{t}\right)+R_{t} b_{n, t} \exp \left(-x_{t}\right)-b_{n, t+1}\right]^{-1}, \\
& b_{n, t+1}=\mu m_{t} p_{n, t}+(1-\mu)(1-\delta) b_{n, t} \exp \left(-x_{t}\right), \\
& h_{t+1} / h_{t}=A\left(p_{n, t} / h_{t}\right)^{\psi} \exp \left(s_{t+1}\right),
\end{aligned}
$$

where equations (A.1) and (A.2) are the first order conditions (14) and (15), equation (A.3) is the household budget constraint (2), equation (A.4) combines the collateral constraint (3) and the law of motion for debt (4), and equation (A.5) is the housing supply function (9). The decision variables are $p_{n, t}, b_{n, t+1}$, and $\eta_{t}$. After substituting in for $\theta_{t}, m_{t}$, and $R_{t}$ using equations (5) through (7), we have seven state variables: $b_{n, t}, h_{t}, u_{t}, v_{t}, \tau_{t}, s_{t}$, and $x_{t}$.

\section{B Appendix: Solution with Rational Expectations}

Under rational expectations, a conjectured solution to the transformed equilibrium conditions (A.1) through (A.5) takes the following form

$$
\begin{aligned}
p_{n, t} / \bar{p}_{n} & \simeq\left(h_{t} / \bar{h}\right)^{\mathrm{a}_{2}} \exp \left[\mathrm{a}_{3} u_{t}+\mathrm{a}_{4} v_{t}+\mathrm{a}_{5} \tau_{t}+\mathrm{a}_{6} s_{t}+\mathrm{a}_{7}\left(x_{t}-\bar{x}\right)\right], \\
\eta_{t} / \bar{\eta} & \simeq \exp \left[\mathrm{f}_{5} \tau_{t}+\mathrm{f}_{7}\left(x_{t}-\bar{x}\right)\right] \\
b_{n, t+1} / \bar{b}_{n} & \simeq\left(b_{n, t} / \bar{b}_{n}\right)^{\mathrm{d}_{1}}\left(h_{t} / \bar{h}\right)^{\mathrm{d}_{2}} \exp \left[\mathrm{d}_{3} u_{t}+\mathrm{d}_{4} v_{t}+\mathrm{d}_{5} \tau_{t}+\mathrm{d}_{6} s_{t}+\mathrm{d}_{7}\left(x_{t}-\bar{x}\right)\right],
\end{aligned}
$$

where $\mathrm{a}_{i}, \mathrm{f}_{i}$, and $\mathrm{d}_{i}$, are solution coefficients. To compute the solution, we take logarithms of equations (A.1) and (A.2) and apply a first-order Taylor series approximation to each equation. The approximation points are the deterministic steady values $\bar{p}_{n}, \bar{b}_{n}, \bar{\eta}, \bar{h}$, and $\bar{x}$. The steady state values of $u_{t}, v_{t}, \tau_{t}$, and $s_{t}$ are zero. The conjectured decision rules (B.1) and (B.2) are iterated ahead one period and used to substitute out $p_{n, t+1}$ and $\eta_{t+1}$ from the approximate versions of (A.1) and (A.2). We evaluate the conditional expectations of the exogenous shocks using the AR(1) laws of motion (5), (6), (7), (8), and (10). After collecting 
terms, the approximate versions of (A.1) and (A.2) are now in the same form as (B.1) and (B.2). The mapping from the actual solution to the conjectured solution pins down the values of the unknown solution coefficients. Finally, we substitute the decision rule for $p_{n, t}$ from (B.1) into the approximate version of (A.4) to obtain the log-linear law of motion for debt (B.3).

For the model simulations shown in Figures 4 and 5, we first construct log-linear approximations of the two objects in equations (A.1) and (A.2) that the household must forecast. We then substitute in the decision rules (B.1) and (B.2) evaluated at time $t+1$. The conditional expectations are computed analytically and substituted into the original nonlinear equilibrium conditions (A.1) and (A.2) to obtain the values of $p_{n, t}$ and $\eta_{t}$ each period. Other endogenous variables evolve according to the exact laws of motion (A.3) through (A.5).

\section{Appendix: Solution with Random Walk Expectations}

We first use equation (A.5) to eliminate $h_{t} / h_{t+1}$ from equation (A.1). The two objects at time $t+1$ that the agent must forecast can now be written as follows:

$$
\begin{aligned}
z_{1, t+1} & \equiv \frac{p_{n, t+1}}{1-\kappa \exp \left(-x_{t+1}\right)} \exp \left(s_{t+1}\right) \\
z_{2, t+1} & \equiv \frac{\exp \left(-x_{t+1}\right)}{1-\kappa \exp \left(-x_{t+1}\right)}\left[R_{t+1}+(1-\mu)(1-\delta) \eta_{t+1}\right]
\end{aligned}
$$

The household's random walk forecast rules take the form $\widehat{E}_{t} z_{1, t+1}=z_{1, t}$ and $\widehat{E}_{t} z_{2, t+1}=$ $z_{2, t}$. Substituting the forecast rules into (A.1) and (A.2) yields the following two equations that are solved each period for $p_{n, t}$ and $\eta_{t}$

$$
\begin{aligned}
p_{n, t} & =\frac{\left[1-\kappa \exp \left(-x_{t}\right)\right] \theta_{t}+\beta A^{-1} h_{t}^{\psi} p_{n, t}^{1-\psi} \exp \left(-s_{t}\right)}{1-\eta_{t} \mu m_{t}} \\
\eta_{t} & =\frac{1-\beta R \exp \left(-x_{t}+\tau_{t}\right)}{1-\beta(1-\mu)(1-\delta) \exp \left(-x_{t}\right)}
\end{aligned}
$$

Given $p_{n, t}$ from the solution of equation (C.3), we solve for $b_{n, t+1}$ each period using equation (A.4). For the reverse-engineering exercise, we also compute log-linear approximations of the decision rules for $p_{n, t}, \eta_{t}$, and $b_{n, t+1}$. The log-linear decision rules take the form

$$
\begin{aligned}
p_{n, t} / \bar{p}_{n} & \simeq\left(h_{t} / \bar{h}\right)^{\widehat{\mathrm{a}}_{2}} \exp \left[\widehat{\mathrm{a}}_{3} u_{t}+\widehat{\mathrm{a}}_{4} v_{t}+\widehat{\mathrm{a}}_{5} \tau_{t}+\widehat{\mathrm{a}}_{6} s_{t}+\widehat{\mathrm{a}}_{7}\left(x_{t}-\bar{x}\right)\right] \\
\eta_{t} / \bar{\eta} & \simeq \exp \left[\widehat{\mathrm{f}}_{6} \tau_{t}+\widehat{\mathrm{f}}_{7}\left(x_{t}-\bar{x}\right)\right] \\
b_{n, t+1} / \bar{b}_{n} & \simeq\left(b_{n, t} / \bar{b}_{n}\right)^{\widehat{\mathrm{d}}_{1}}\left(h_{t} / \bar{h}\right)^{\widehat{\mathrm{d}}_{2}} \exp \left[\widehat{\mathrm{d}}_{3} u_{t}+\widehat{\mathrm{d}}_{4} v_{t}+\widehat{\mathrm{d}}_{5} \tau_{t}+\widehat{\mathrm{d}}_{6} s_{t}+\widehat{\mathrm{d}}_{7}\left(x_{t}-\bar{x}\right)\right],
\end{aligned}
$$

which look similar to equations (B.1) through (B.3), but the solution coefficients $\widehat{\mathrm{a}}_{i}, \widehat{\mathrm{f}}_{i}$, and $\widehat{\mathrm{d}}_{i}$ are different from those in the rational expectations solution. For example, we have $\widehat{a}_{3}=0.547$ 
in equation (C.5) versus $\mathrm{a}_{3}=0.195$ in equation (B.1). This explains why the random walk model can match the volatility of the variable $p_{n, t}$ in the data with a smaller standard deviation for the housing preference shock $u_{t}$. 


\section{References}

Adam, Klaus., P. Kuang, and Albert Marcet (2012) "House Price Booms and the Current Account." In NBER Macroeconomics Annual 2011, edited by Daron Acemoglu and Michael Woodford, pp. 77-122. Chicago: University of Chicago Press.

Adam, Klaus, Albert Marcet, and Johannes Beutel. (2017) "Stock Price Booms and Expected Capital Gains." American Economic Review, 107, 2352-2408.

Adrian, Tobias, and Hyun Song Shin. (2010) "Financial Intermediaries and Monetary Economics." In Handbook of Monetary Economics 3, edited by Benjamin M. Friedman and Michael Woodford, pp. 601-650. New York: Elsevier.

Alpanda, Sami, and Sarah Zubairy. (2017) "Addressing Household Indebtedness: Monetary, Fiscal or Macroprudential Policy?" European Economic Review, 92, 47-73.

Barsky, Robert B., and J. Bradford De Long. (1993) "Why Does the Stock Market Fluctuate?" Quarterly Journal of Economics, 107, 291-311.

Berkovec, James A., Yan Chang, and Douglas A. McManus. (2012) "Alternative Lending Channels and the Crisis in U.S. Housing Markets." Real Estate Economics, 40, Special Issue No. 1, S8-S31.

Bhutta Neil, and Benjamin J. Keys. (2016) "Interest Rates and Home Equity Extraction During the Housing Boom." American Economic Review, 106, 1742-1774.

Boz, Emine, and Enrique G. Mendoza. (2014) "Financial Innovation, the Discovery of Risk, and the U.S. Credit Crisis." Journal of Monetary Economics, 62, 1-22.

Burnside, Craig, Martin Eichenbaum, and Sergio Rebelo. (2016) "Understanding Booms and Busts in Housing Markets." Journal of Political Economy, 124, 1088-1147.

Campbell, Sean D., Morris A. Davis, Joshua Gallin, and Robert F. Martin. (2009) "What Moves Housing Markets: A Variance Decomposition of the Price-Rent Ratio." Journal of Urban Economics, 66, 90-102.

Case, Karl E., Robert J. Shiller, and Anne K. Thompson. (2012) "What Have They Been Thinking? Home Buyer Behavior in Hot and Cold Markets." Brookings Papers on Economic Activity, Fall, 265-298.

Chari, V.V., Patrick J. Kehoe, and Ellen R. McGrattan. (2007) "Business Cycle Accounting." Econometrica, 75, 781-836.

Chen, Hui, Michael Michaux, and Nikolai Roussanov. (2013) "Houses as ATMs? Mortgage Refinancing and Macroeconomic Uncertainty." NBER Working Paper No. 19421.

Coibion, Olivier, and Yuriy Gorodnichenko. (2015) "Information Rigidity and the Expectations Formation Process: A Simple Framework and New Facts." American Economic Review, 105, 2644-2678.

Davis, Morris A., Andreas Lehnert, and Robert F. Martin. (2008) "The Rent-Price Ratio for the Aggregate Stock of Owner-Occupied Housing." Review of Income and Wealth, 54, 279-284.

Dell'Ariccia, Giovanni, Deniz Igan, and Luc Laeven. (2012) "Credit Booms and Lending Standards: Evidence from the Subprime Mortgage Market." Journal of Money Credit and Banking, 44, 367-384.

Demyanyk, Yulia S., and Otto Van Hemert. (2011) "Understanding the Subprime Mortgage Crisis." Review of Financial Studies, 24, 1848-1880.

Dokko, Jane, Brian Doyle, Michael T. Kiley, Jinill Kim, Shane Sherlund, Jae Sim, and Skander Van den Heuvel. (2011) "Monetary Policy and the Global Housing Bubble." Economic Policy, $26,237-287$. 
Duca, John V., John Muellbauer, and Anthony Murphy. (2010) "Housing Markets and the Financial Crisis of 2007-2008: Lessons for the Future." Journal of Financial Stability, 6, 203217.

Duca, John V., John Muellbauer, and Anthony Murphy. (2011) "House Prices and Credit Constraints: Making Sense of the U.S. Experience." Economic Journal, 121, 533-551.

Dudley, William C. (2017) "Evolving Consumer Behavior." Remarks at the National Retail Federation Annual Convention. New York City, January 17, 2017.

Engsted, Tom, Simon J. Hviid, and Thomas Q. Pedersen. (2016) "Explosive Bubbles in House Prices? Evidence from the OECD Countries." Journal of International Financial Markets, Institutions and Money, 40, 14-25.

Favilukis, Jack, Sydney C. Ludvigson, and Stijn Van Nieuwerburgh. (2017) "The Macroeconomic Effects of Housing Wealth, Housing Finance, and Limited Risk-Sharing in General Equilibrium." Journal of Political Economy, 125, 140-223.

Garriga, Carlos, Rodolfo E. Manuelli, and Adrian Peralta-Alva. (2017) "A Macroeconomic Model of Price Swings in the Housing Market." Manuscript.

Gelain, Paolo, Kevin J. Lansing, and Caterina Mendicino. (2013) "House Prices, Credit Growth, and Excess Volatility: Implications for Monetary and Macroprudential Policy." International Journal of Central Banking, 9(2), 219-276.

Gelain, Paolo, and Kevin J. Lansing. (2014) "House Prices, Expectations, and Time-Varying Fundamentals." Journal of Empirical Finance, 29, 3-25.

Gelain, Paolo., Kevin J. Lansing, and Gisle J. Natvik. (2018) "Leaning Against the Credit Cycle." Journal of the European Economic Association, forthcoming.

Gete, Pedro. (2017) "Expectations and the Housing Boom and Bust: An Open Economy View." Manuscript.

Glaeser, Edward L., Joshua D. Gottlieb, and Joseph Gyourko. (2013) "Can Cheap Credit Explain the Housing Boom?" In Housing and the Financial Crisis, edited by in Edward L. Glaeser and Todd Sinai, pp. 301-360. Chicago: University of Chicago Press.

Glaeser, Edward L., and Charles G. Nathanson. (2018) "An Extrapolative Model of House Price Dynamics." Journal of Financial Economics, forthcoming.

Glick, Reuven, and Kevin J. Lansing. (2010) "Global Household Leverage, House Prices and Consumption." Federal Reserve Bank of San Francisco, Economic Letter, 2010-01 (January 11).

Goetzmann, William N., Liang Peng and Jacqueline Yen. (2012) "The Subprime Crisis and House Price Appreciation." Journal of Real Estate Finance and Economics, 44, 36-56.

Granziera, Eleonora, and Sharon Kozicki. (2015) "House Price Dynamics: Fundamentals and Expectations." Journal of Economic Dynamics and Control, 60, 152-165.

Greenspan, Alan. (2005) "Consumer Finance." Remarks at the Federal Reserve System's Fourth Annual Community Affairs Research Conference, Washington, D.C., April 8, 2005.

Greenspan, Alan. and James E. Kennedy. (2008) "Sources and Uses of Equity Extracted from Homes." Oxford Review of Economic Policy, 24, 120-144.

Greenwood, Robin, and Andrei Shleifer. (2014) "Expectations of Returns and Expected Returns." Review of Financial Studies, 27, 714-746.

Himmelberg, Charles, Christopher Mayer, and Todd Sinai. (2005) "Assessing High House Prices: Bubbles, Fundamentals, and Misperceptions." Federal Reserve Bank of New York, Staff Report No. 218 (September). 
Iacoviello, Matteo, and Stefano Neri. (2010) "Housing Market Spillovers: Evidence from an Estimated DSGE Model." American Economic Journal: Macroeconomics, 2, 125-164.

Iacoviello, Matteo. (2015) "Financial Business Cycles." Review of Economic Dynamics, 18, 140-163.

International Monetary Fund. (2012) "Dealing with Household Debt." In World Economic Outlook Chapter 3, Growth Resuming, Dangers Remain, (April).

Jiménez, Gabriel, Steven Ongena, Jose-Luis Peydró, Jesús Saurina. (2014) "Hazardous Times for Monetary Policy: What do Twenty-Three Million Bank Loans Say About the Effects of Monetary Policy on Credit Risk?" Econometrica, 82, 463-505.

Jurgilas, Marius, and Kevin J. Lansing. (2013) "Housing Bubbles and Expected Returns to Home Ownership: Lessons and Policy Implications." In Property Prices and Real Estate Financing in a Turbulent World, edited by Morten Balling and Jesper Berg, pp. 101-128. Brussels/Vienna: Société Universitaire Européenne de Recherches Financières (SUERF).

Jordà, Òscar, Moritz Schularick, and Alan M. Taylor. (2015) "Betting the House." Journal of International Economics, 96 (S1), S1-S18.

Justiniano, Alejandro, Giorgio Primiceri, and Andrea Tambalotti. (2015) "Household Leveraging and Deleveraging." Review of Economic Dynamics, 18, 3-20.

Justiniano, Alejandro, Giorgio Primiceri, and Andrea Tambalotti. (2017) "Credit Supply and the Housing Boom." Manuscript.

Kermani, Amir. (2012) "Cheap Credit, Collateral and the Boom-Bust Cycle." Manuscript.

Koijen, Ralph S. J., Maik Schmeling, and Evert B. Vrugt. (2015) "Survey Expectations of Returns and Asset Pricing Puzzles." Manuscript.

Kydland, Finn E., Peter Rupert, and Roman Šustek. (2016) "Housing Dynamics Over the Business Cycle." International Economic Review, 57, 1149-1177.

Laibson, David and Johanna Mollerstrom. (2010) "Capital Flows, Consumption Booms and Asset Bubbles: A Behavioral Alternative to the Savings Glut Hypothesis." Economic Journal, 120, 354-374.

Lansing, Kevin J. (2006) "Lock-In of Extrapolative Expectations in an Asset Pricing Model." Macroeconomic Dynamics, 10, 317-348.

Lansing, Kevin J., (2010) "Rational and Near-Rational Bubbles Without Drift." Economic Journal, 120, 1149-1174.

Lansing, Kevin J., and Agnieszka Markiewicz. (2018) "Top Incomes, Rising Inequality, and Welfare." Economic Journal, 128, 262-297.

Ling, David C., Joseoh T. L. Ooi, and Thao T. T. Le. (2015) "Explaining House Price Dynamics: Isolating the Role of Nonfundamentals." Journal of Money Credit and Banking, 47 (S1), 87-125.

Lucas, Robert E. (1978) "Asset Prices in an Exchange Economy," Econometrica, 46, 14291445.

McDonald, John F., and Houston H. Stokes. (2011) "Monetary Policy and the Housing Bubble." Journal of Real Estate Finance and Economics, 46, 437-451.

McCarthy, Jonathan, and Richard W. Peach. (2004) "Are Home Prices the Next Bubble?" Federal Reserve Bank of New York, Economic Policy Review, 10(3), 1-17.

Mian, Atif, and Amir Sufi. (2009) "The Consequences of Mortgage Credit Expansion: Evidence from the U.S. Mortgage Default Crisis." Quarterly Journal of Economics, 124, 14491496. 
Mian, Atif, and Amir Sufi. (2014) "House Price Gains and U.S. Household Spending from 2002 to 2006." NBER Working Paper No. 20152.

Nerlove, Mark. (1967) "Distributed Lags and Unobserved Components in Economic Time Series." In Ten Economic Studies in the Tradition of Irving Fischer, edited by William Fellner, pp. 127-169. New York: John Wiley and Sons.

Pavlov, Andrey, and Susan M. Wachter. (2011) "Subprime Lending and Real Estate Prices." Real Estate Economics, 39, 1-17.

Piazzesi, Monika, and Martin Schneider. (2009) "Momentum Traders in the Housing Market: Survey Evidence and a Search Model." American Economic Review Papers and Proceedings, 99, 406-411.

Taylor, John B. (2007) "Housing and Monetary Policy." Paper presented at symposium sponsored by the Federal Reserve Bank of Kansas City, Jackson Hole, Wyoming (September 1).

U.S. Financial Crisis Inquiry Commission. (2011) Final Report on the Causes of the Financial and Economic Crisis in the United States. Washington D.C.: U.S. Government Printing Office. 
Figure 1: U.S. Housing Market Boom and Bust
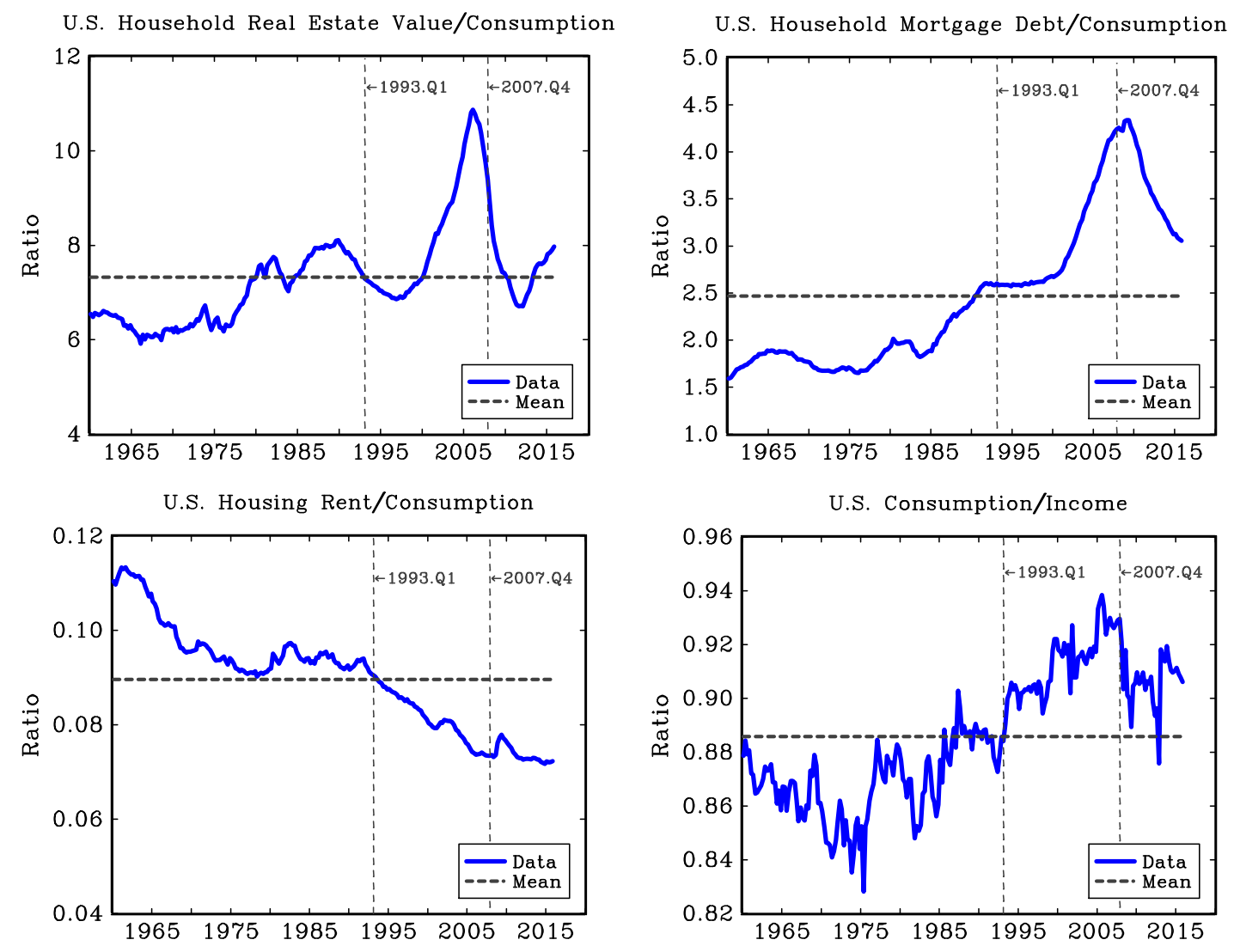

Notes: Starting around the mid-1990s, the U.S. economy experienced correlated booms and busts in household real estate value, mortgage debt, and personal consumption expenditures. In contrast, the ratio of housing rent to consumption declined steadily over the same period. The ratio of housing value to consumption peaked in 2006.Q1, seven quarters prior to the start of the Great Recession in 2007.Q4. The ratio of mortgage debt to consumption peaked somewhat later in 2009.Q1. The ratio of personal consumption expenditures to personal disposable income peaked in 2005.Q3. For consistency with the model, consumption, disposable income, and housing rent are converted to quarterly flow measures. The median house price and rent series in the data are both scaled (preserving the price-to-rent ratio) so that the ratio of the median house price to per capita consumption in 1993.Q1 coincides with the ratio of aggregate housing value to aggregate consumption in the same quarter, implying a normalized housing supply of 1.0 in 1993.Q1. 
Figure 2: Housing Supply Variables
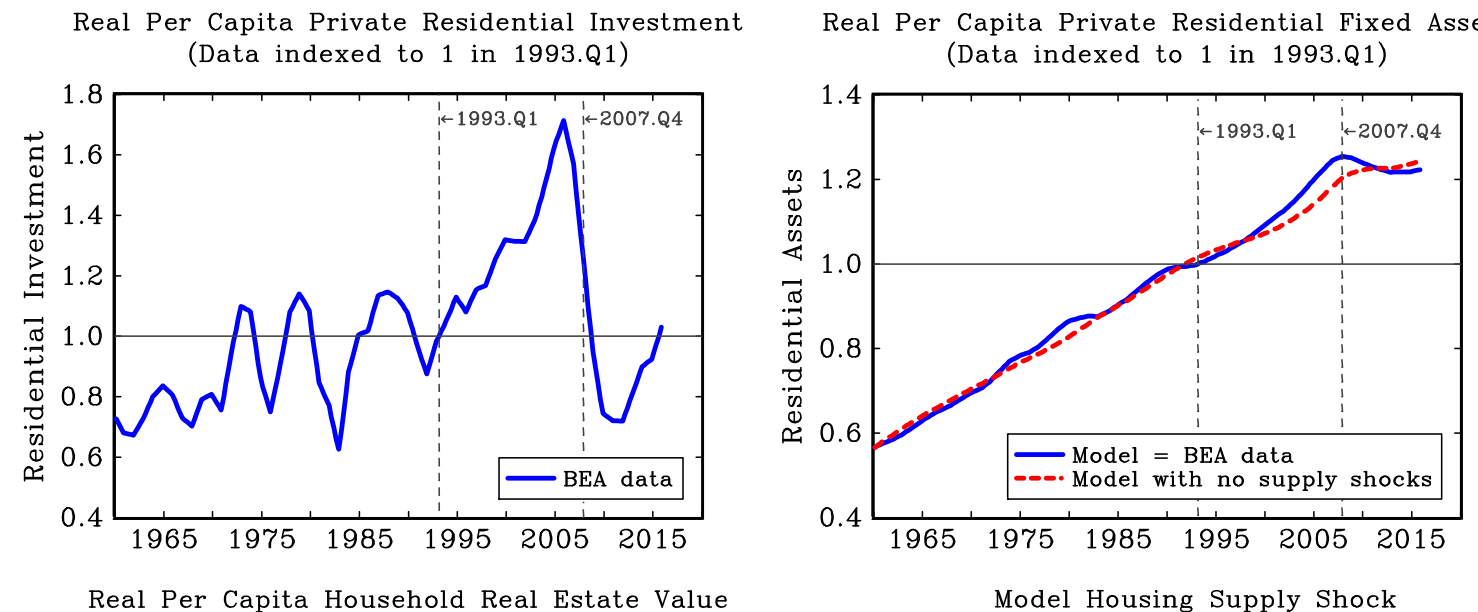

Real Per Capita Household Real Estate Value (Data indexed to 1 in 1993.Q1)
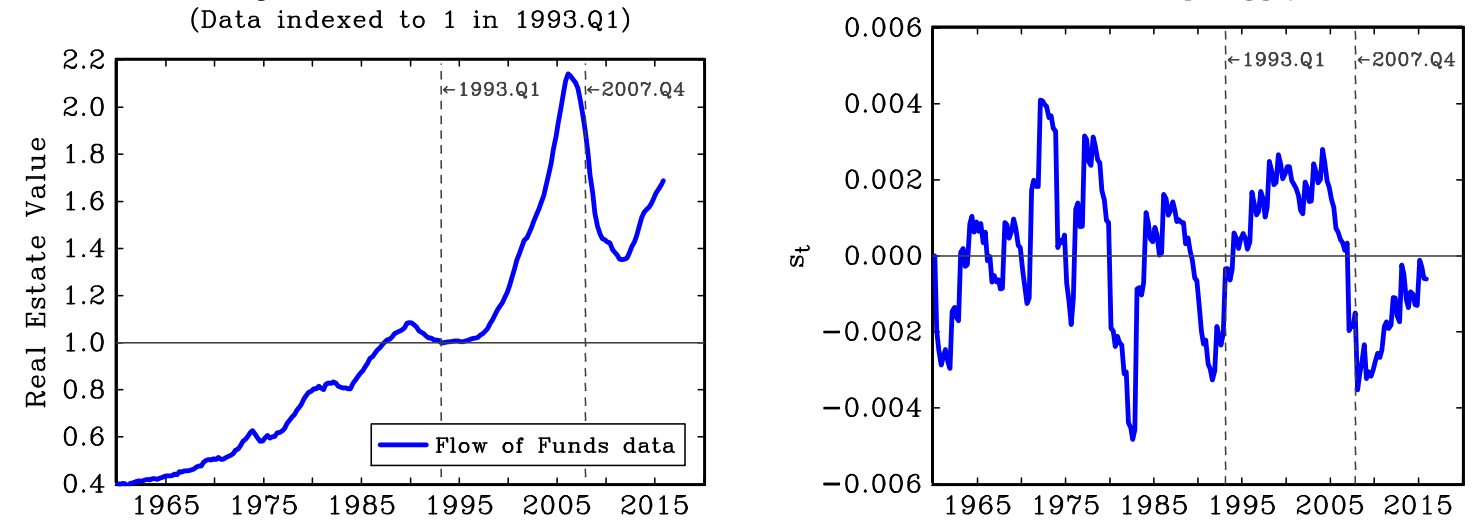

Notes: Housing supply in the model is governed by equation (9). The elasticity parameter $\psi$ is estimated from data on the BEA's chain-type quantity index for the net stock of private residential fixed assets. The realizations of the housing supply shock $s_{t}$ are computed to allow the model to exactly replicate the path of private residential fixed assets in the data. 
Figure 3: Assessing the Performance of Random Walk Forecast Rules in U.S. Data
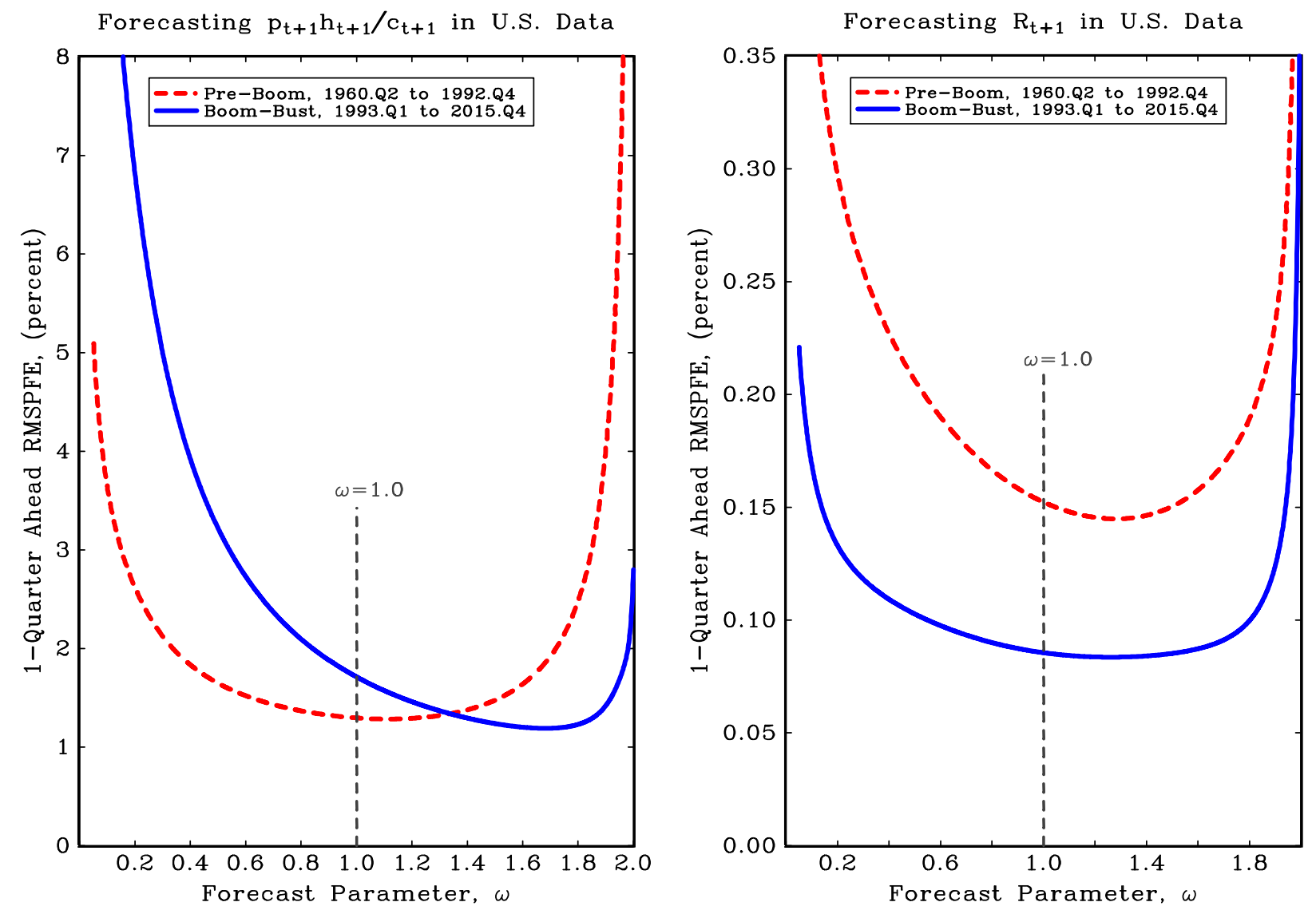

Notes: The figure plots the root mean squared percentage forecast error (RMSPFE) for one-quarter ahead forecasts of each variable using a forecast rule of the form $\widehat{E}_{t} z_{t+1}=\omega z_{t}+(1-\omega) \widehat{E}_{t-1} z_{t}$, where $z_{t+1} \in$ $\left\{p_{t+1} h_{t+1} / c_{t+1}, R_{t+1}\right\}$. Random walk expectations correspond to the case of $\omega=1$ which does not sacrifice much in forecast performance relative to higher values of $\omega$. 
Figure 4: Simulations with Model-Specific Shocks
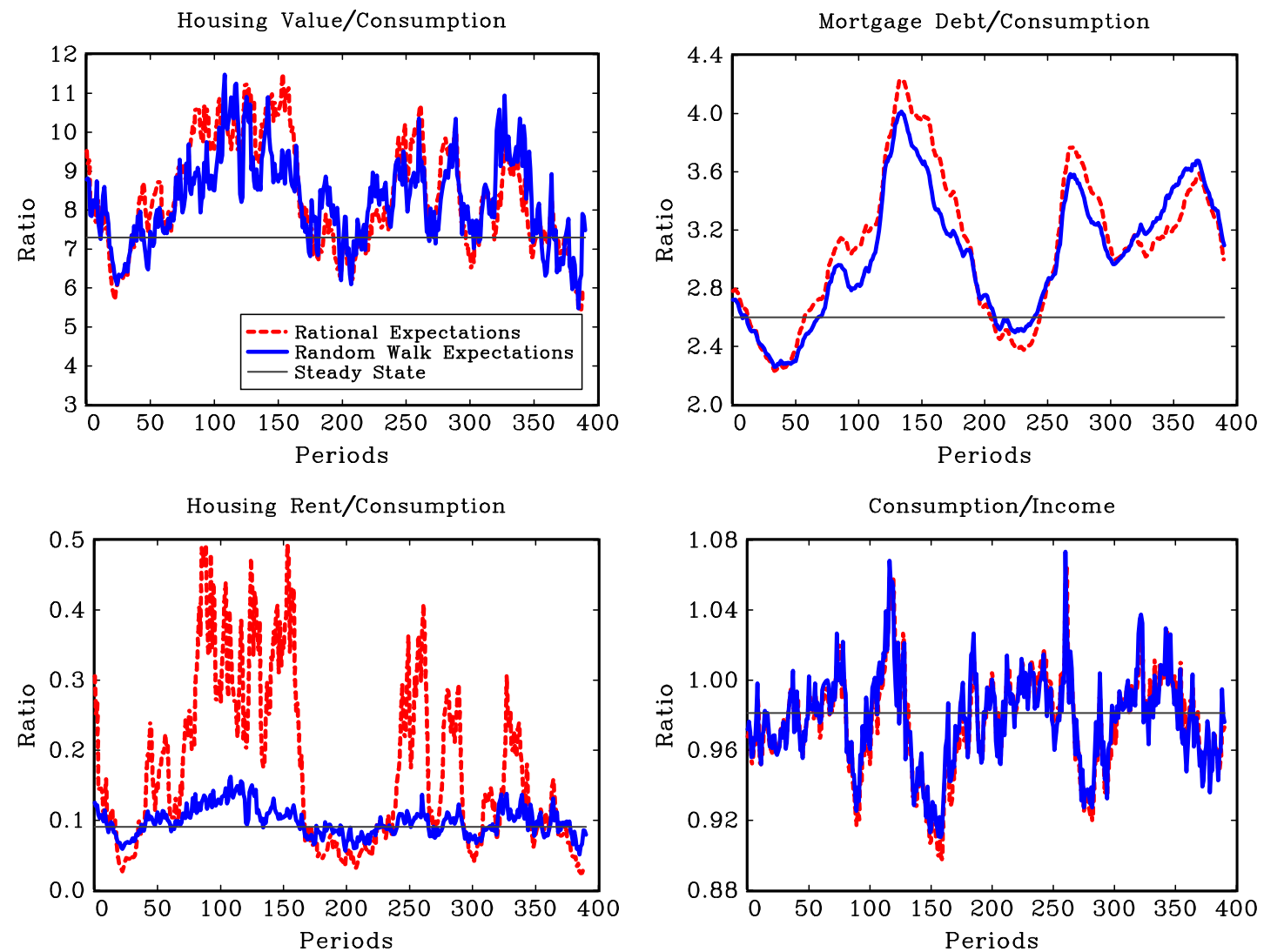

Notes: The four panels are the model-generated versions of the corresponding U.S. data ratios plotted earlier in Figure 1. The standard deviation of shock innovations in each model is chosen to match the volatilities of the housing value-to-consumption ratio and the mortgage debt-to-consumption ratio in U.S. data. With random walk expectations, only a small housing preference shock is needed to match the volatility of the housing value-to-consumption ratio. The rent-to-consumption ratio exhibits low volatility, similar to the data. With rational expectations, a highly volatile housing preference shock is needed to match the volatility of the housing value-to-consumption ratio. The result is a highly volatile rent-to-consumption ratio, which is counterfactual. 
Figure 5: Impulse Response Functions with Common Shocks
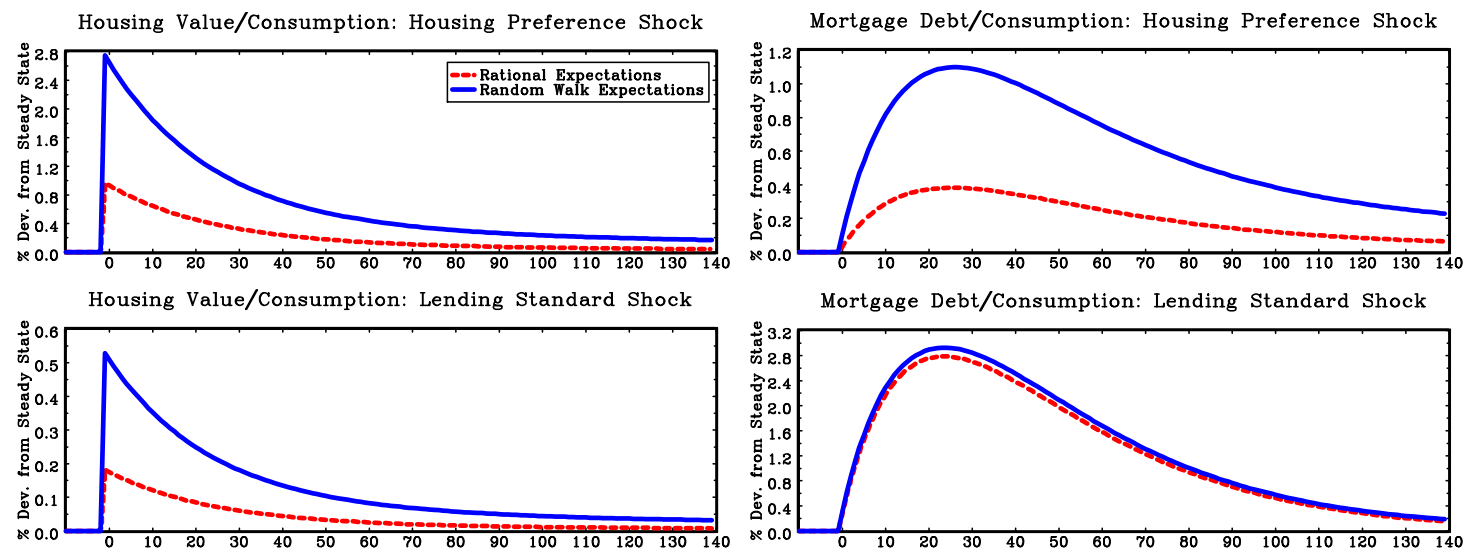

Mortgage Debt/Consumption: Lending Standard Shock
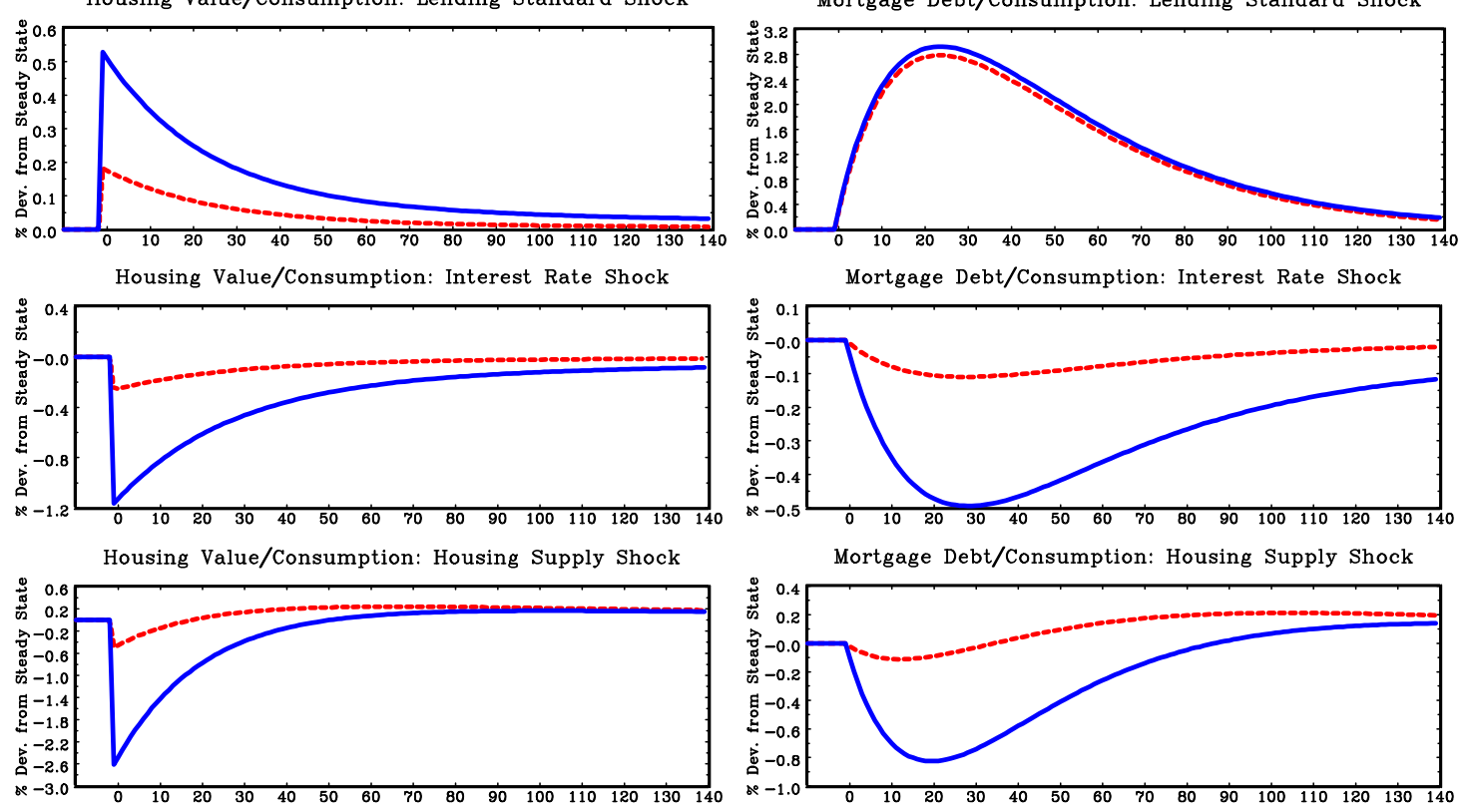

Notes: In each panel, the models are hit with the same one-standard deviation positive shock innovation. The model with random walk expectations exhibits excess volatility relative to the model with rational expectations. 
Figure 6: Reverse-Engineering Shocks to Match the U.S. Data

U.S. Per Capita Consumption Growth

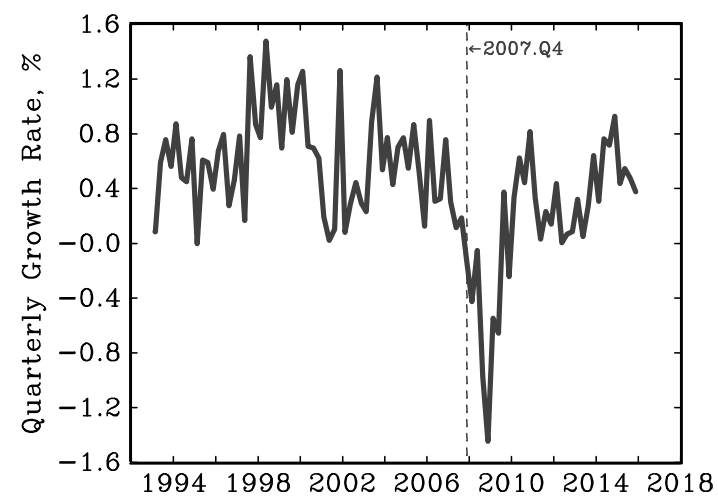

Model Implied Housing Preference Variable

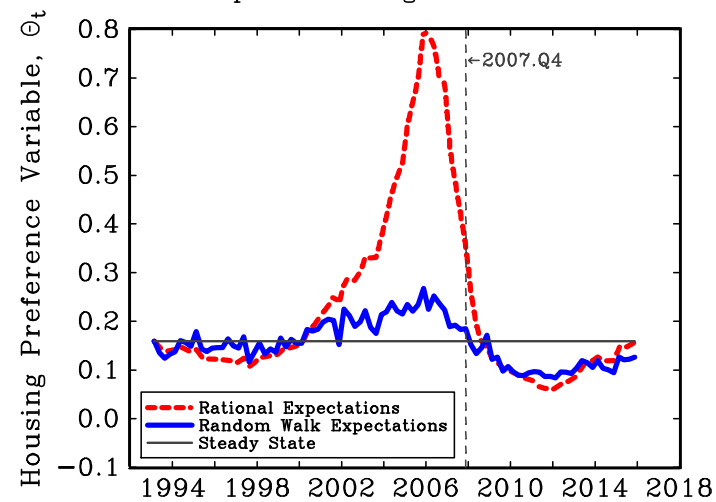

U.S. 30-year Conventional Real Mortgage Rate

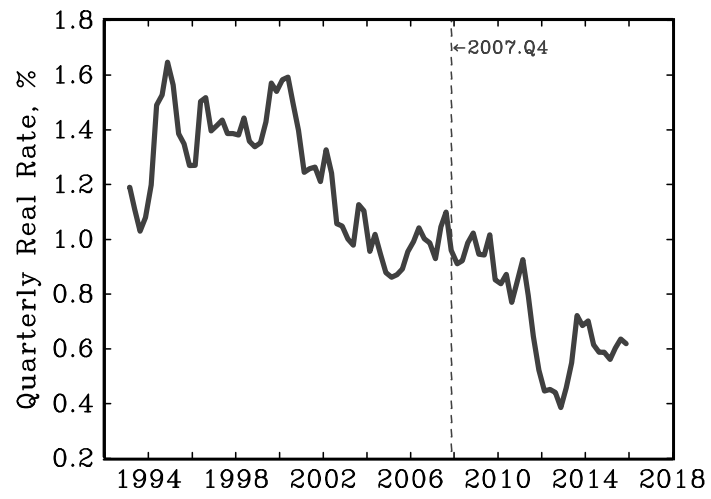

Model Implied Lending Standard Variable

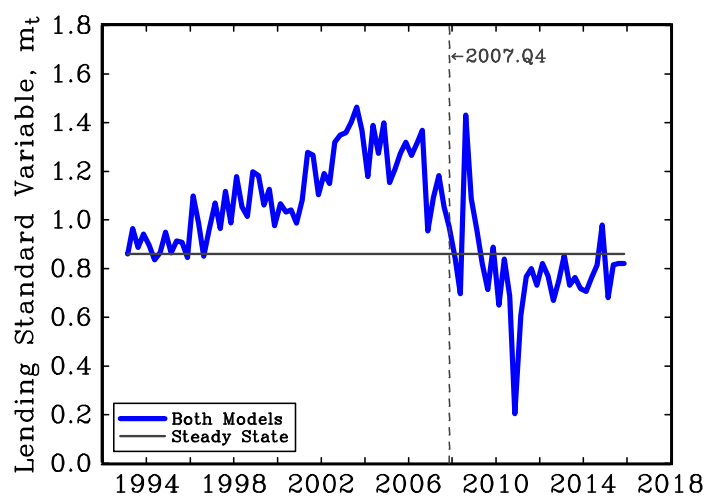

Notes: As inputs to the reverse-engineering exercise, the model variables $x_{t}, R_{t}$, and $h_{t}$ take on the values observed in the data. The U.S. time series for $x_{t}$ and $R_{t}-1$ are plotted in the top panels above, while the time series for $h_{t}$ is plotted in the top right panel of Figure 2. The bottom panels show the paths of the reverseengineered housing preference variable $\theta_{t}$ and lending standard variable $m_{t}$ that are needed to exactly replicate the time paths of the U.S. housing value-to-consumption ratio and the U.S. mortgage debt-to-consumption ratio. The model with random walk expectations can match the data with much smaller movements in the housing preference variable $\theta_{t}$. Conditional on matching the time paths of the U.S. ratios, both models imply the same pattern for the lending standard variable $m_{t}$. 
Figure 7: Net Percentage of U.S. Banks Tightening Lending Standards

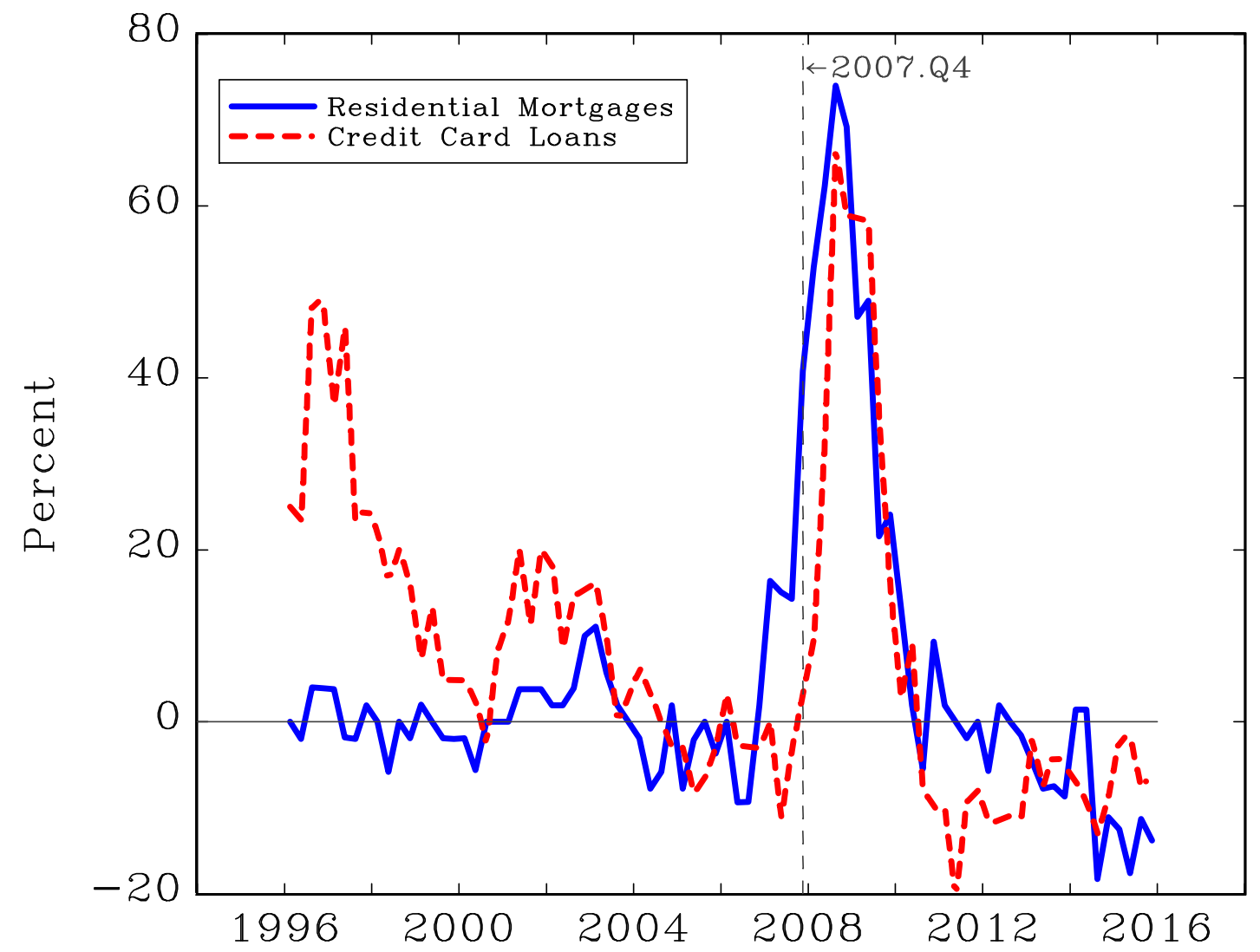

Notes: Two indicators of lending standard tightness from the Federal Reserve's Senior Loan Officer Opinion Survey (SLOOS). Both series show that banks started to tighten lending standards before the onset of the Great Recession in 2007.Q4. Moreover, a substantial percentage of banks continued to tighten standards even after the recession ended in 2009.Q2. 
Figure 8: Model Implied Paths for Other Macroeconomic Variables
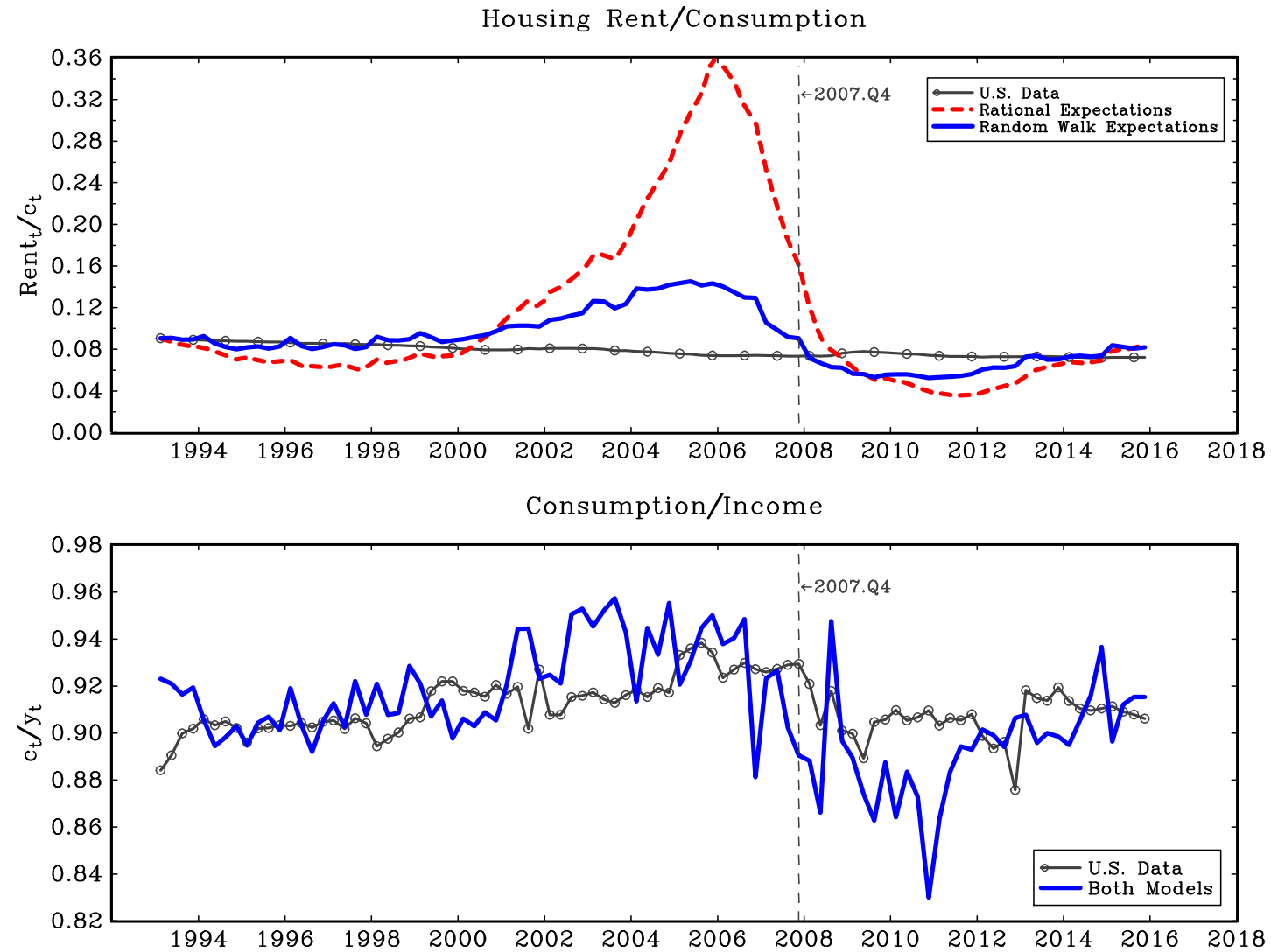

Notes: In the model with rational expectations, the large reverse-engineered housing preference shocks generate a large boom-bust cycle in the rent-to-consumption ratio. In the model with random walk expectations, the much smaller reverse-engineered housing preference shocks generate less movement in the rent-to-consumption ratio, which is closer to the pattern observed in the data. By construction, both models imply identical hump-shaped paths for the consumption-to-income ratio. 
Figure 9: Counterfactual Scenarios

No Housing Preference Shock

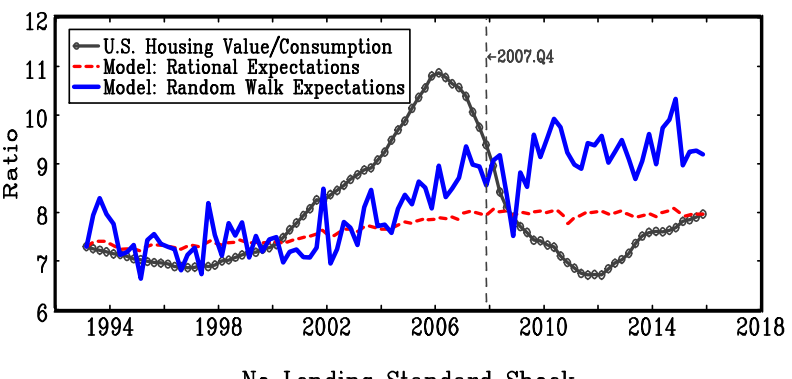

No Lending Standard Shock

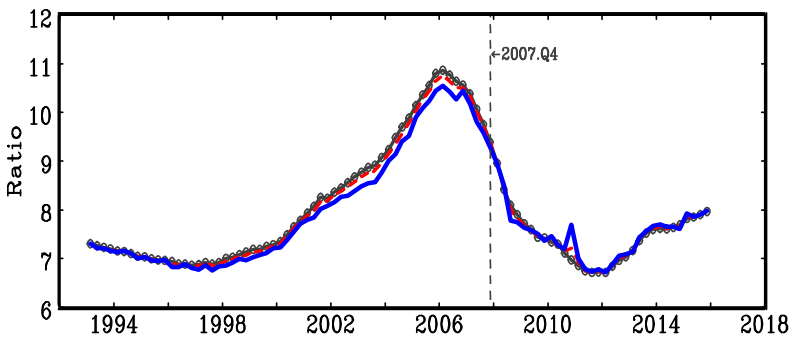

No Mortgage Interest Rate Shock
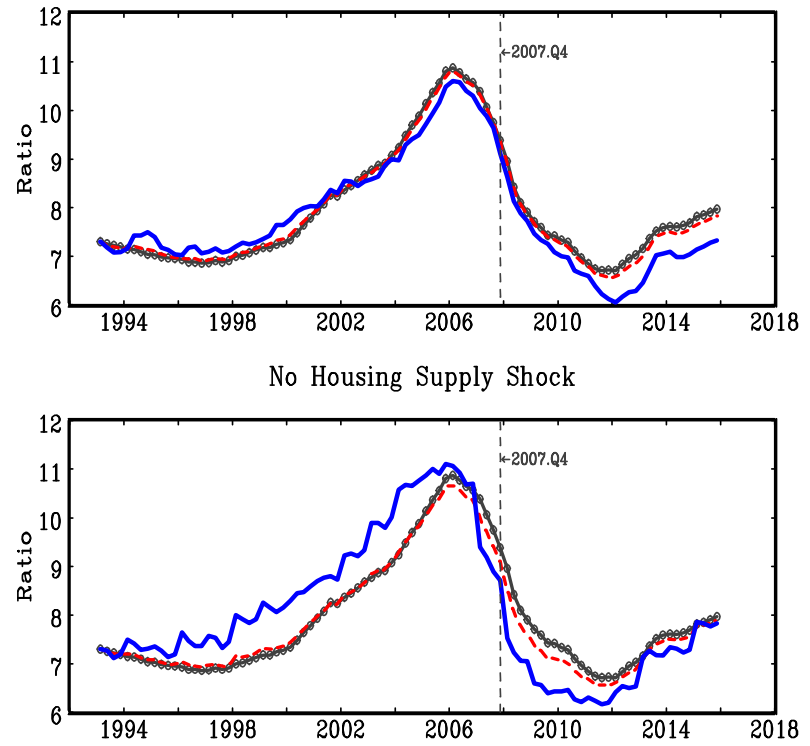

No Housing Preference Shock

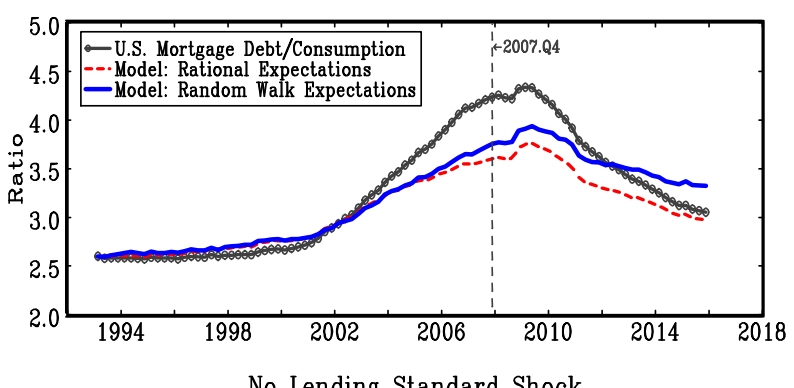

No Lending Standard Shock

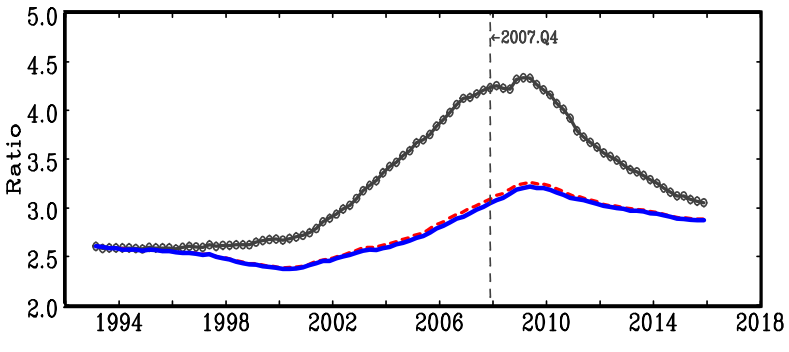

No Mortgage Interest Rate Shock
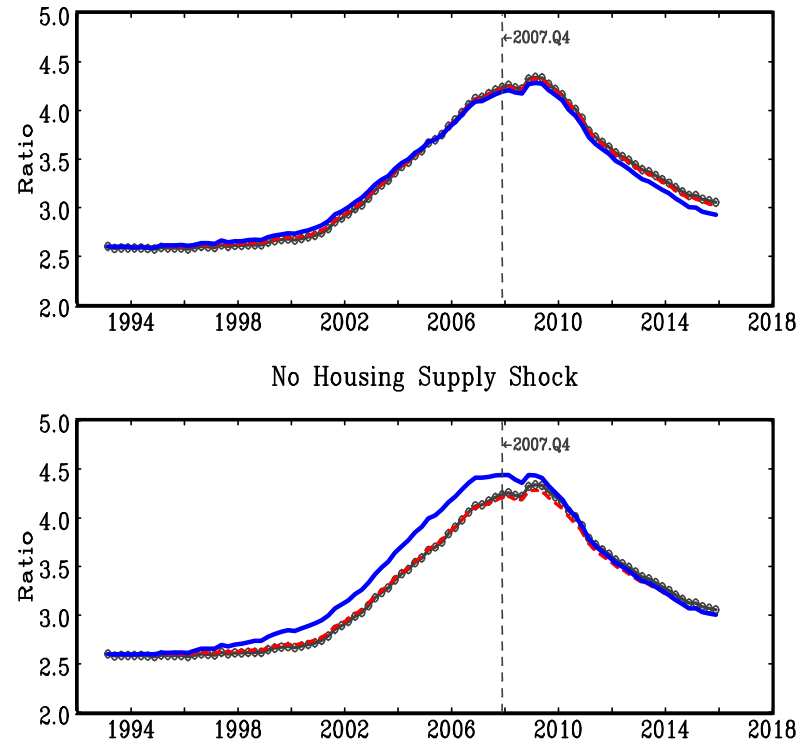

Notes: The figure shows the effects of shutting off one shock at a time on housing value (left panels) and mortgage debt (right panels), while leaving the other shocks unchanged. A large gap between the model counterfactual path and the U.S. data path (black line) implies that the omitted shock plays an important role in allowing the model to match the U.S. data. 